\title{
Pastores de puna del periodo Horizonte Medio en el Callejón de Huaylas, Perú
}

\author{
Víctor Ponte*
}

\begin{abstract}
Resumen
Sobre la base de investigaciones arqueológicas desarrollada en tres sitios localizados en el área de influencia de la Mina Pierina, Callejón de Huaylas, Perú, se ha podido reunir evidencia para inferir que un grupo de pastores se instaló en la puna y explotó este medio geográfico exclusivamente durante el período Horizonte Medio (650-950 AD). La ocupacion temporal ha sido confirmada por mediciones radiocarbónicas que concuerdan con los estilos cerámicos y líticos para la época. Es posible que hubo un incremento en el consumo de textiles por el estado Wari, lo cual alentó la instalación de centros rurales en áreas de altura tal como Ancosh Punta. Se asume interacción regional controlada por el estado Wari, especialmente para la obsidiana, el único elemento importado en el corpus geológico local de materia prima para la manufactura de instrumentos líticos. Esta fue trasladada desde Ayacucho y Arequipa. Sin embargo, se observa también patrones locales en la manufactura de vasijas cerámicas y puntas de proyectil así como en la construcción funeraria de chullpas rectangulares con ajuar compuesto de elementos simbólicos que reflejan la interacción Wari.
\end{abstract}

Palabras claves

Pastoralismo, Obsidiana, Horizonte Medio, Cerámica, Textiles, Recuay, fechados radiocarbónicos

\begin{abstract}
Archaeological data obtained from three sites located on the Pierina mining influence area, Callejón Huaylas, Perú have gathered evidence to argue for pastoralism operations during the Middle Horizon period (650 950 AD). This epoch saw a rise of llama herds. The temporal occupation has been confirmed by radiocarbon measurements that are agreed with ceramic and lithic local styles. It is suggest a possible increment on the consumption of textile by Wari State, which propelled rural centers such as Ancosh Punta. Regional interaction is assumed by the Wari control of obsidian sources, the only imported raw material for manufacturing lithic tools. Obsidian found in Pierina was obtained from Ayacucho (Quizpisisa source) and Arequipa (Alca source). However, local patterns remain the same specially in the manufacture of ceramic vessels, projectile points, and the building of rectangular funerary chullpa construction with offerings were composed of symbolic elements that reflect Wari interaction.
\end{abstract}

Key words

Pastoralum, Middle Horizon, ceramics, textiles, Recuay, radiocarbon dates.

\footnotetext{
*Correo electrónico: ponte@wisc.edu
} 
La forma de expansión del Imperio Wari sobre los Andes Nor-Centrales del Perú podría explicarse por la complejidad de previas entidades sociopolíticas que se localizaron en la periferia del imperio, a considerable distancia del valle de Ayacucho. La instalación de centros administrativos Wari en zonas periféricas dependería de las condiciones de organización política y población de las sociedades conquistadas (Jennings y Craig 2001). La preexistencia de una sociedad pre-estatal desarrollada durante el Intermedio Temprano denominada Recuay, pudo ser un obstáculo en el avance conquistador Wari pero también su incorporación podría haber motivado un cambio cualitativo en la región fortaleciendo la actividad constructiva, la interacción regional y la economía local. Schreiber (1992:33) ha argumentado que una de las formas de expansión de los estados es a partir de la utilización de una previa infraestructura política en la región conquistada que conlleva a un control gubernamental indirecto de supervisión.

Si bien la sociedad Recuay mostró un desarrollo independiente, se observa sobre la base de la evidencia, que en el Callejón de Huaylas durante el Período Horizonte Medio hubo nuevas formas de administración y organización territorial para la obtención de recursos, como por ejemplo, especialistas en la adquisición de productos de altura. Al parecer, hubo algún tipo de reorganización política y económica vinculada muy estrechamente a intereses Wari. Uno de los principales proyectos del estado Wari pudo haber sido el aliento, adquisición y administración de mayor ganado camélido. El pastoreo de camélidos fue un recurso económico enteramente útil y un mecanismo de supervivencia para sociedades de altura (Stone Miller 1992:337). El aprovechamiento de la llama como elemento de transporte y carga, el uso de fibra lanar de alpacas y vicuñas silvestres para la elaboración de finos textiles, así como su constante empleo en sacrificios para ceremonias pudieron constituir entre otras razones (Shimada y Shimada 1985), bienes económicos de suma importancia para la administración Wari. Si bien durante el Periodo Intermedio Temprano con Recuay existió producción textil sobre la base de lana de camélidos, su existencia es casi desconocida. Últimamente, dos tejidos Recuay sin procedencia han sido analizados confirmándose cierta similitud a la estructura de túnicas Wari (Rodman \& Fernández 2000: fig. 34,35). La carencia de tejidos Recuay contrasta fuertemente con el caso Wari, donde espectaculares textiles, túnicas y uncus han sido recuperados de tumbas costeñas (Kaulicke 1997, 2000; Prümers 2000; Angeles \& Pozzi-Escot 2000) siendo menor el número obtenido de tumbas serranas debido a problemas de conservación (Murra 1975:147). La frecuencia de telares Wari induce a pensar que el pastoreo de camélidos fue una actividad prioritaria para el estado, el cual dio materia prima para la especializada producción artesanal textil. A pesar de su extensión (Miller \& Burger 1995:424), los recursos de la puna altoandina del Callejón de Huaylas no son muy variados, mayormente sólo crecen pastos naturales de ichu que fueron aprovechados para la crianza de llamas y alpacas. Actualmente, rara vez son vistas vicuñas (Bonavia 1996:61), las cuales han sido reintroducidas en el Parque Nacional Huascarán (Bartle 1985:13), mientras que cérvidos y tarugos sí son frecuentemente advertidos.

La ocupación humana en esta alta elevación fue estacional, establecida principalmente en abrigos rocosos y practicada desde el precerámico a través de circuitos de caza temporales. El sistema migratorio no sólo fue benéfico para sociedades tempranas, sino que también fue mantenido por sociedades pastoriles (Lynch 1971:140). En Chavín de Huántar el pastoreo fue una actividad menor complementaria a la agrícola, estando los asentamientos localizados en el piso inferior suni/quechua, asimismo, el consumo de carne de camélidos y en menor medida cérvidos 
estuvo siendo explotado durante el Horizonte Temprano habiendo una preferencia por el consumo de camélidos jóvenes especialmente para la élite dirigente del templo de Chavín de Huántar ((Miller \& Burger 1995:449). A pesar de ello, ya se utilizaba la llama como animal de carga. La organización económica no es totalmente diferente en el Periodo Medio donde se consumía carne de camélidos indiscriminadamente jóvenes y adultos tal como reporta Denise Pozzi-Escot (1991:86) para Conchopata. No obstante, se infiere que este patrón sólo se da en la clase dirigente y no para el común de la población.

Todavía no es bien sabido cómo fue la incorporación del Callejón de Huaylas por el Imperio Wari, aunque puede haber sido dirigido desde el centro administrativo provincial Honco Pampa (Isbell 1991;1989;1988), el cual conserva el patrón arquitectónico característico de patios rectangulares y cuartos alargados denominados "grupos-patio", similares a la capital Wari y también existente en la temprana capital de Conchopata (Isbell 2000:22-23). Sin embargo, la albañilería que exhiben los muros y la construcción funeraria chullpa están también presentes en Honco Pampa y en la región en general siendo un fuerte componente local mantenido desde el Periodo Intermedio Temprano pese a los cambios foráneos obligados por Wari.

\section{El desarrollo local de la cultura Recuay}

Después del declive de la unificación religiosa Chavín, surgió en el Callejón de Huaylas un fuerte cacicazgo local llamado Recuay (200 600 $\mathrm{AD})$ caracterizado por la decoración geométrica en cerámica y que empleó la técnica de pintura en negativo/positivo y modelado sobre arcilla blanca de caolín. Los temas representados en la escultura lítica, en la cerámica y en los pocos textiles recuperados indican supremacía de señores y jefes militares mediante una fuerte estratificación política (Fig. 1), la que es acompañada por una serie de símbolos religiosos y representada a través de una compleja iconografía de serpientes bicéfalas, cabezas trofeo, camélidos, felinos rodeando a un personaje central y un animal mítico llamado el ser aserrado o lunar (Moseley 1999:192; Ponte 2000; Grieder 1978:fig.162; Lau 2000; Makowski y Rucabado al 2000). El núcleo del asentamiento Recuay incluyó las estribaciones y colinas elevadas de las Cordilleras Blanca y Negra con amplio dominio del territorio formado por el río Santa, cuyo valle interandino y quebradas laterales fueron aprovechados esporádicamente para la práctica de la agricultura desde el piso del valle hasta los límites de la puna (2,500 3,700 msnm). Asimismo, los recursos de puna $(3,8004,500 \mathrm{msnm})$ fueron explotados por sociedades Recuay. La presencia de restos de extensos corrales en áreas con bofedales y la constante repetición de camélidos como elemento de transporte acompañados por un personaje político importante en la iconografía cerámica (ver por ejemplo Lumbreras 1980: lámina XIII; Bennett 1944: plate 2; Eisleb 1987; Lau 2000:fig.10; Makowski Rucabado 2000:fig.35; Bonavia 1996:fotografía 22), señalan la importancia del recurso camélido como soporte de la economía Recuay. Por otro lado, en la puna del flanco occidental de la Cordillera Negra existieron instalaciones Recuay debido probablemente al control hidráulico procedente de lagunas. Varias lagunas tienen evidencia de haber sido represadas y canalizadas para controlar el regadío de los valles occidentales interandinos y la parte alta de los valles costeños (cf. Gambini 1984:110; Samaniego 1992, comunicación personal). Al este, en la Cordillera Blanca, además de ocupar las quebradas de penetración a los glaciares, hay sitios arqueológicos Recuay en pasos naturales que cruzan la cordillera nevada donde existen caminos que comunican a la zona oriental interandina y la cuenca del Marañón. Al margen de la sierra, materiales Recuay se encuentran en casi todos los valles 


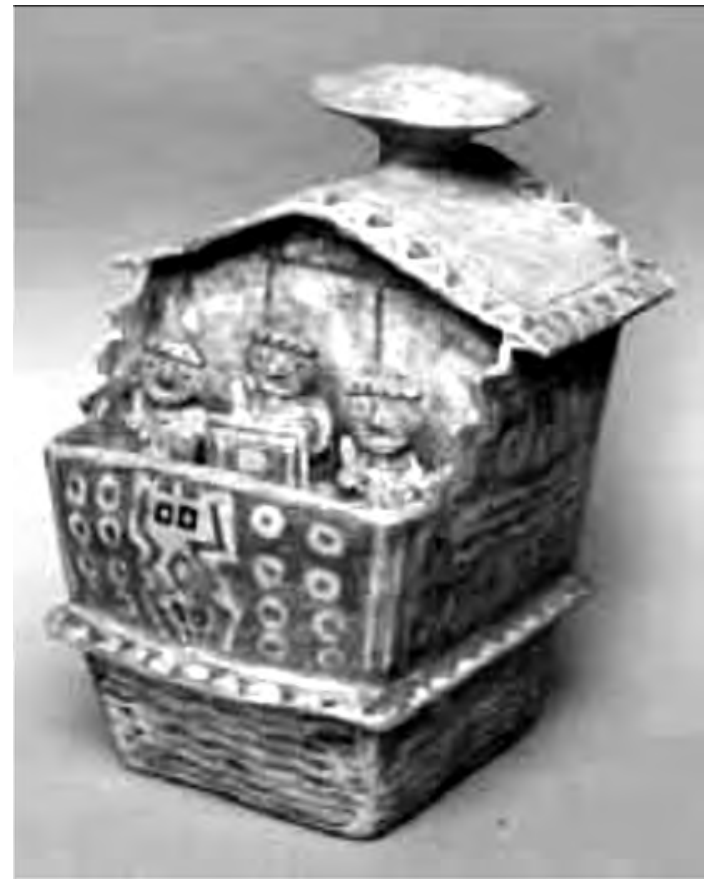

Figura 1. Personaje Recuay rodeado de sirvientes.

altos costeños del departamento de Ancash y también en la parte sur de La Libertad donde hubo contactos con Moche, sobretodo a nivel ideológico, demarcándose bien los límites de ambos (Makowski y Rucabado 2000; Wilson 1988; 1995; Proulx 1982; Larco Hoyle s/f; Kent 2003, comunicación personal). La penetración Recuay en la sierra norte llegó hasta la región de Huamachuco, notándose allí cerámica y escultura lítica del sitio Pashash (cf. Mc Cown 1945: 17, 20; Topic y Topic 2000:194) y quizás llegando hasta la cuenca del mismo Marañon. El declive del estilo Recuay aparece a mediados y fines del 600 AD cuando la cerámica deja de tener la calidad de antes; las tumbas subterráneas dejan de emplearse y aparecen nuevas construcciones funerarias sobre la superficie acompañados de formas y estilos cerámicos asociados al Wari Norteño. Así también aparece un nuevo patrón constructivo de arquitectura planificada con planta rectangular y cuartos alargados en su inte- rior alrededor de un patio central. Lo mismo que la construcción ceremonial en forma de D. Sitios como Honco Pampa, Anta Pampa y Pariamarca poseen estas características. Sin embargo, el dominio Wari sobre el Callejón de Huaylas no es sólo a través de la supuesta instalación de estos nuevos centros administrativos. Construcciones religiosas y funerarias acompañando a los centros o sin éstos, son localizados con mayor frecuencia a lo largo del valle interandino en ambas márgenes y a mayor elevación. Esta simbiosis entre templos funerarios y centros administrativos no se da propiamente en la capital Wari ni en otros centros administrativos del sur del Perú. Podría ser explicado por una combinación de factores sociales de tradición regional desde el Intermedio Temprano, expresados en una nueva forma de arquitectura pero con dominio ideológico Wari.

\section{Pastoreo durante el Horizonte Medio: La puna de Pierina, Cordillera Negra}

La meseta altoandina en el área de la mina Pierina a una altitud promedio de 4,100 msnm en el lado oriental de la Cordillera Negra (Fig. 2) se caracteriza por una topografía ondulante y moderadamente empinada. Quebradas empinadas en el lado nor-oriental definen el piso ecológico inferior mientras que al oeste de la planicie se encuentra el valle profundo del sistema quebrada Cuncashca/río Llancash el cual desemboca en el río Santa (Fig. 3). Esta región tiene un clima de Tundra Seco característico de la alta montaña con variaciones de la temperatura entre los 15 a $6^{\circ} \mathrm{C}$ dependiendo de la nubosidad. La flora cultivada en el área de puna es limitada. Los cultivos sólo existen en laderas de menor altitud mientras que en la altiplanicie sólo se encuentran pastos naturales tipo ichu y un tipo de cactus Oroya borchersii en peligro de extinción. Dos especies de árboles leñosos tipo queñoa (Polylepis racemosa y weberbaueri) existen en el área de estudio lo mismo que una arbustiva lla- 
mada tsacpä (Oreocallis grandiflora), ésta última fue utilizada para confeccionar canastas y en cestería. Ambas plantas crecen sobretodo en zonas de vertientes. Durante la estación húmeda, una variedad de pequeñas plantas y flores con propiedades medicinales crecen en la pampa altoandina entre roquedales. Es muy probable que han sido conocidas en el pasado. Una de éstas se llama Ancosh o Anqush (Senecio canescens)
(Kolff et al 1997:138) precisamente el nombre de un sitio arqueológico (plano 3). Es una hierba cuyas hojas son denominadas "Orejas de Venado" por su semejanza. Crece en zonas altas de la puna entre 4,100 a 4,400 m y es asociada a temperaturas frías. Sin embargo, en el área de Ancosh Punta no encontramos este tipo de planta. Los campesinos locales mencionaron haberla visto en la alta y desolada puna "donde el frío es

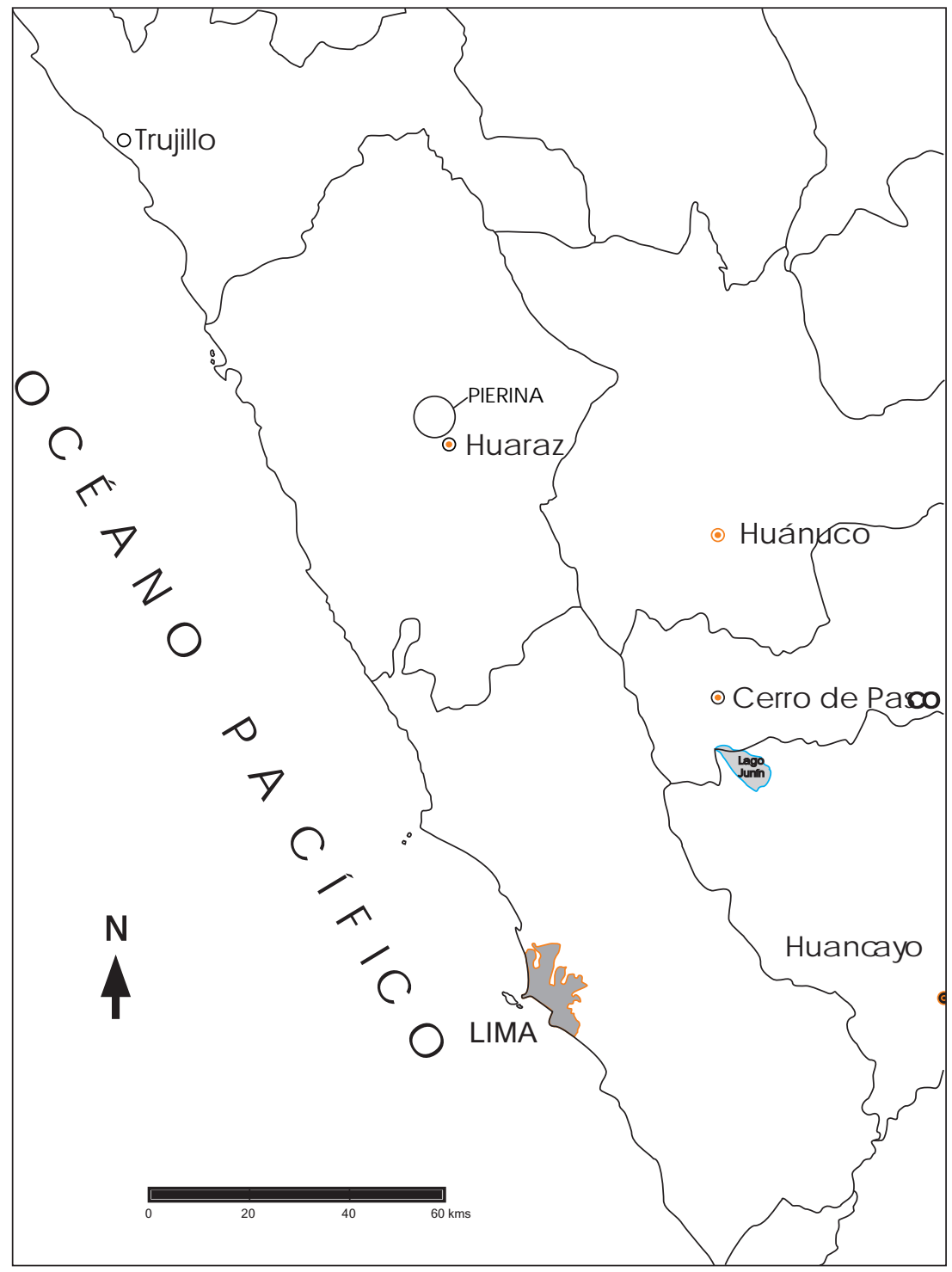

Figura 2. Mapa general de localización de Mina Pierina. 


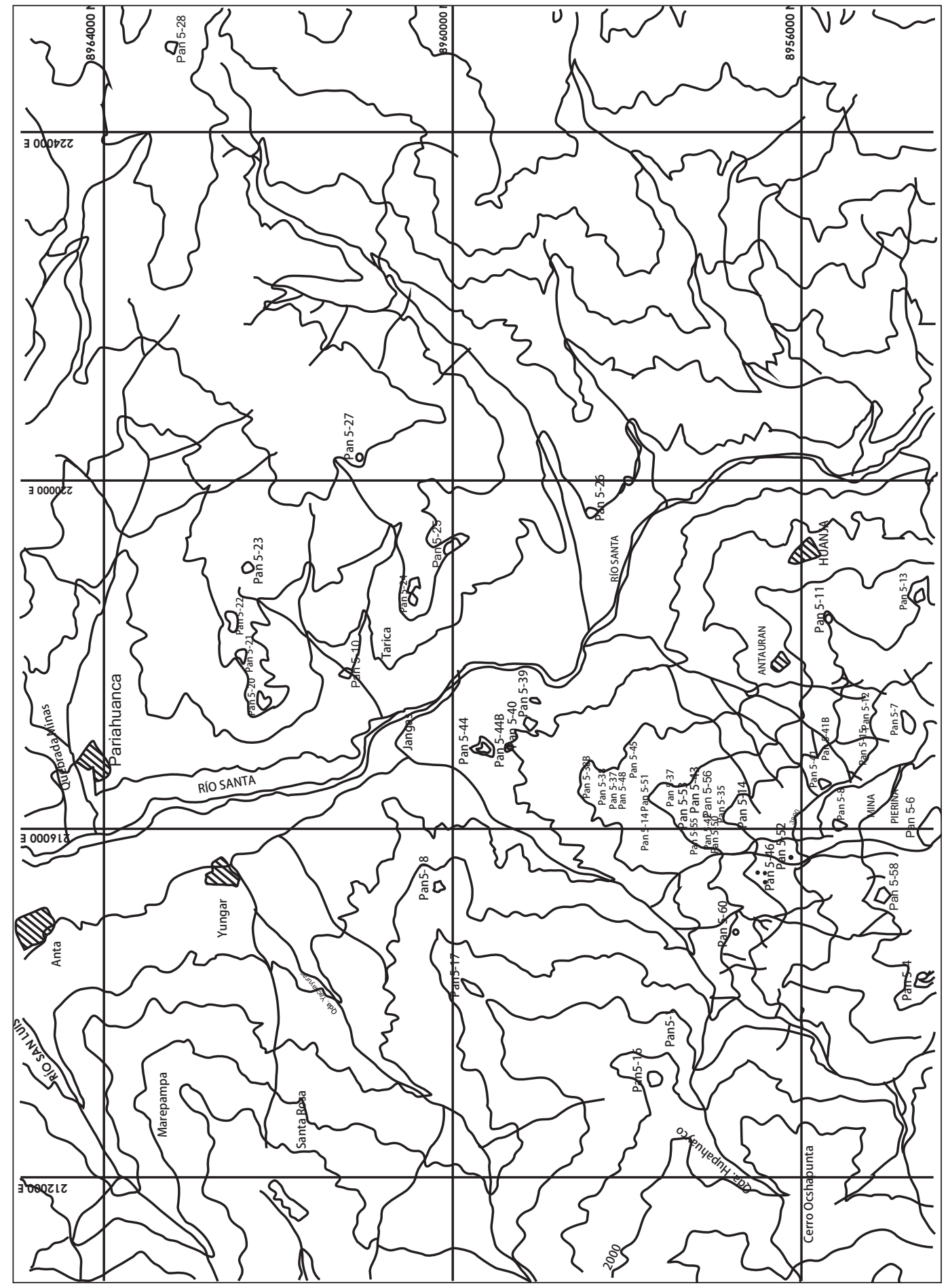

Figura 3. Plano de los sitios arqueológicos en el área de influencia de Mina Pierina. 
más fuerte”. Quizás durante el 600 AD la temperatura era más fría y propició el desarrollo de esta planta que actualmente ha migrado a un piso más elevado.

Aunque no es muy concluyente, Lonnie G. Thompson (1995:628), sobre la base de sus estudios en los nevados Huascarán (Ancash) y Quelccaya (Cuzco) indica que concentraciones de partículas de polvo en muestras del 400 a 620 $\mathrm{AD}$ y 830 a $960 \mathrm{AD}$ asociadas a granodiorita procedente de la Cordillera Blanca son vinculadas a eventos dramáticos registrados en Quelccaya con altos índices de polvo que sugieren intensa actividad agrícola en el altiplano del Titicaca (Thompson et. al 1988). En términos generales la temperatura en los glaciales y en altas elevaciones puede haber sido $8^{\circ}$ a $12^{\circ}$ C más fría que el presente a consecuencia del gradual enfriamiento que culminó en una pequeña edad de hielo (Thompson et.al. 1995:46). Este dato puede confirmar el hábitat más frío de la puna que propició el mayor requerimiento de vestido proporcionado por la fibra lanar de los camélidos.

El recurso hídrico fue muy importante para las poblaciones antiguas. Los asentamientos humanos prefirieron instalarse cerca de fuentes de agua y puquios especialmente si se trata de comunidades de pastores. Las excavaciones en el abrigo rocoso Llaca Amá Caca (PAn 5-58), localizado en el extremo noroeste de la planicie en la mina Pierina, han evidenciado una fuerte presencia de camélidos y cérvidos (Rofes 1999) que aprovechaban los pastos propiciados por ciénagas y puquiales. Los monitoreos de aguas subterráneas efectuados por la Compañía Minera Barrick Misquichilca S.A. consisten en la instalación de pozos fijos en distintos puntos en el área de puna, uno de éstos pozos (PS3-1) está localizado en el perímetro del sitio arqueológico tratado (Fig. 4), y, las mediciones permanentes apoyan la importancia hídrica que tuvo este lugar. Aún en época seca, la fluidez del agua de este pozo es constante. Según versiones de los campesinos en este sitio brotaba un pequeño manantial el cual era especialmente importante pues mantenía una zona húmeda y cenagosa con el crecimiento de pastos. Hubo sostenida presencia del hombre en este lugar desde épocas precerámicas. Esto se basa en el análisis de la tipología de puntas de proyectil (Grimaldo 1999), donde existen pequeñas puntas con base redondeada semejantes a los tipos precerámicos del Complejo II de Guitarrero: Quishqui Puncu 5 y Lampas 10 (Lynch 1980:fig 9.6). El complejo precerámico II es datado entre 8,500 5,700 AC (Lynch 1970:1309). La estacionalidad y constante migración entre pisos altitudinales para el aprovechamiento de distintos recursos, ha podido estar siendo practicado hasta tiempos bastante más tardíos a pesar de la agricultura y cerámica (Lynch 1967:780). Sin embargo, este manuscrito se concentra en el Horizonte Medio, período en el cual las sociedades eran más complejas con individuos cumpliendo funciones especializadas y cuando la inversión energética en la producción lítica fue menor (Bencic 2000). A continuación se analiza el sitio de Ancosh Punta y su implicancia en el pastoralismo durante el Horizonte Medio.

\section{Ancosh Punta (PAn 5-5)}

El sitio arqueológico se sitúa en una suave colina con bajos desniveles a manera de pampa en plena ecología de puna a 4,190 m de elevación (Fig.5). Contiene varios corrales de pirca moderna de planta ovalada, donde se contaron entre 10 a 12 recintos bastante grandes $(6 \times 10 \mathrm{~m}$ aproximadamente). Los muros modernos estaban hechos de piedras toscas de origen volcánico con formas irregulares que se disponían sin mayor orden. Sin embargo, estos cubrían pesadas rocas que pueden haber sido los originales corrales antiguos y recinto de habitación asociado. Una estructura habitacional de forma rectangular con un lado abierto en forma de U estaba insertada entre los gruesos muros de pirca que 
forman los corrales. Las excavaciones se centraron en ésta estructura con un lado abierto, un recinto que continuaba siendo utilizado hasta tiempos recientes como habitación estacional de pastores modernos (Fig. 6).

\section{Estructura habitacional tipo Masma en la puna}

Una simple construcción de pirca moderna se asentaba sobre un muro mejor elaborado de doble cara con piedras labradas unidos con argamasa. Tuvo altura promedio de $0.50 \mathrm{~m}$ y no fue

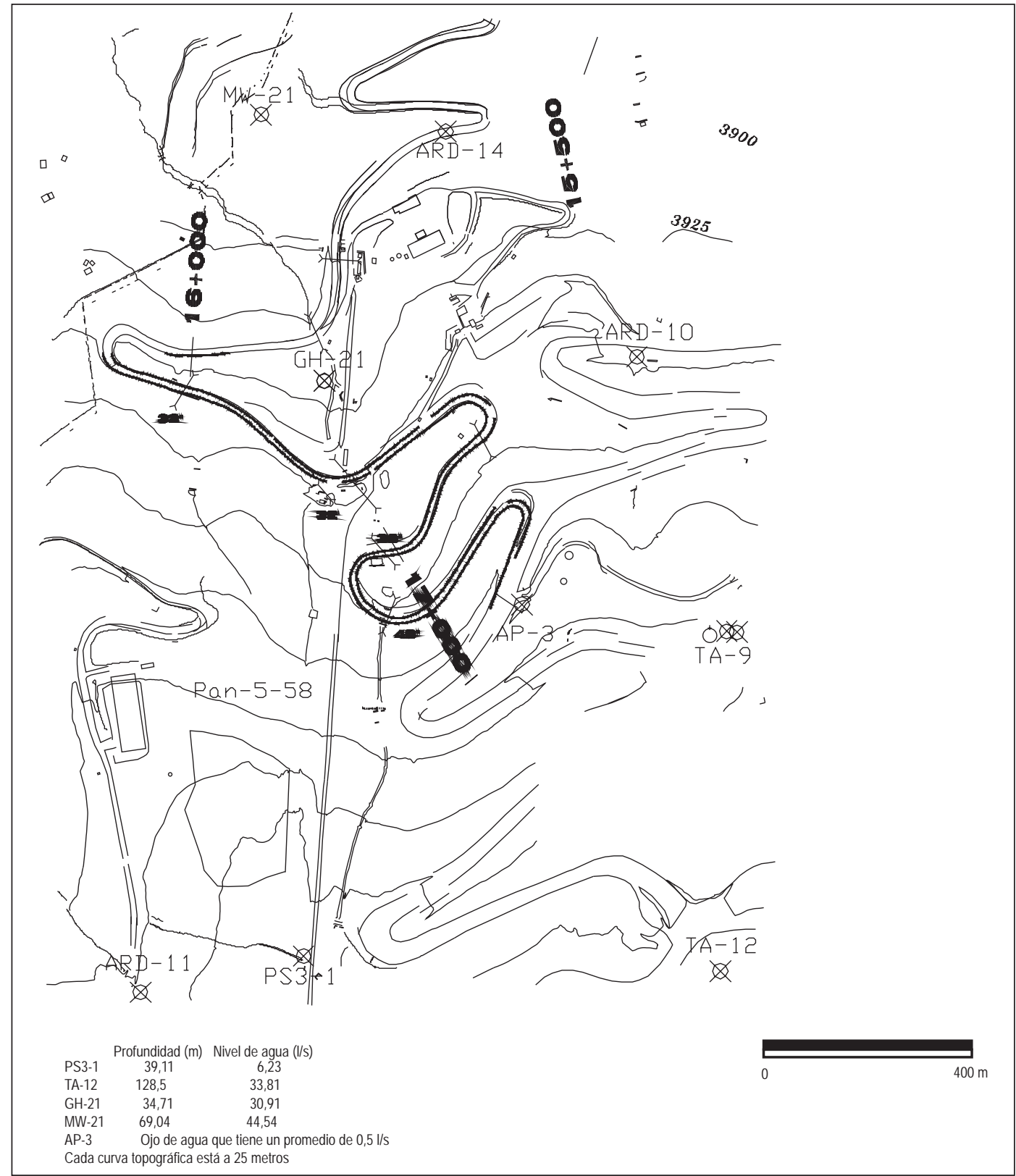

Figura 4. Plano de localización del sitio Llaca Amá Caca (PAn 5-58) y ubicación de pozos de control de aguas subterráneas 


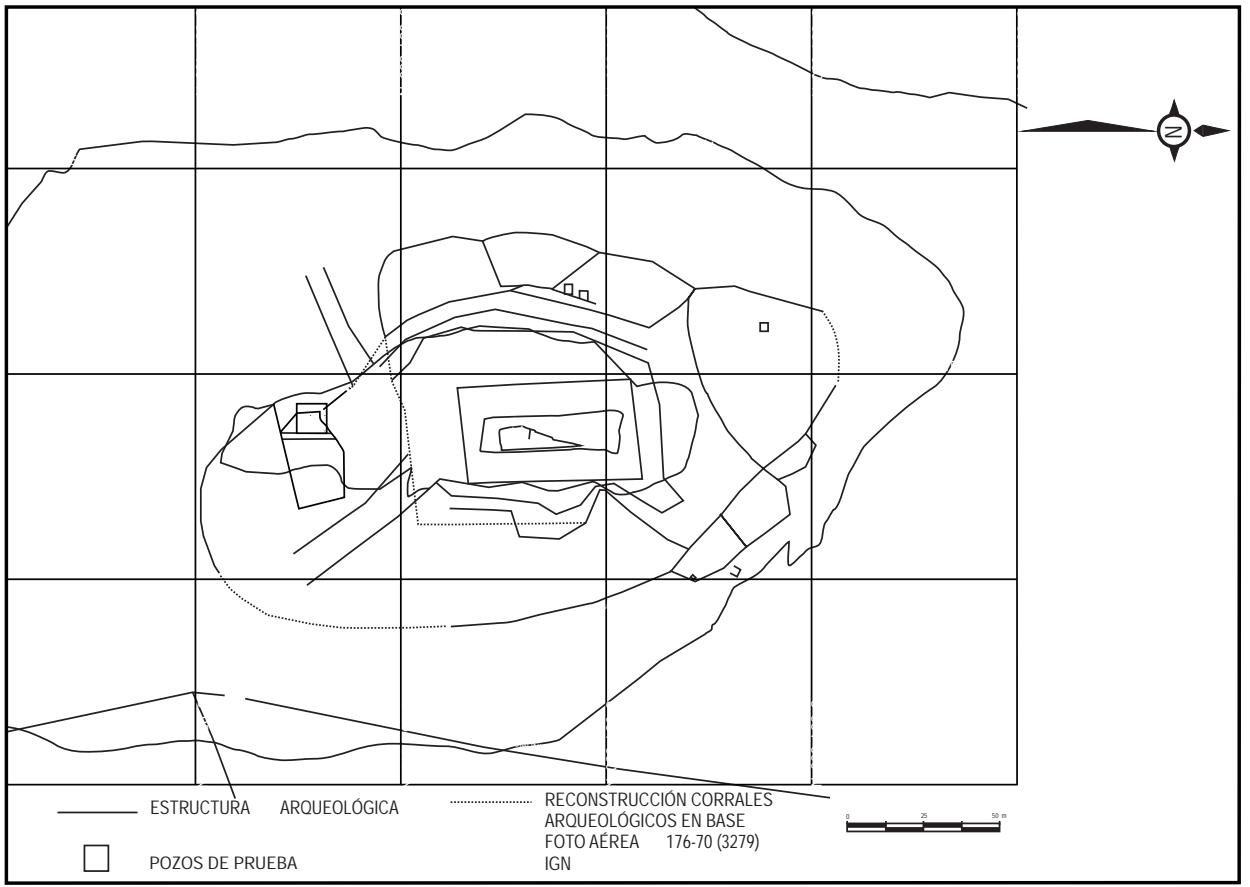

Figura 5. Plano de Ancosh punta (PAn 5-5).

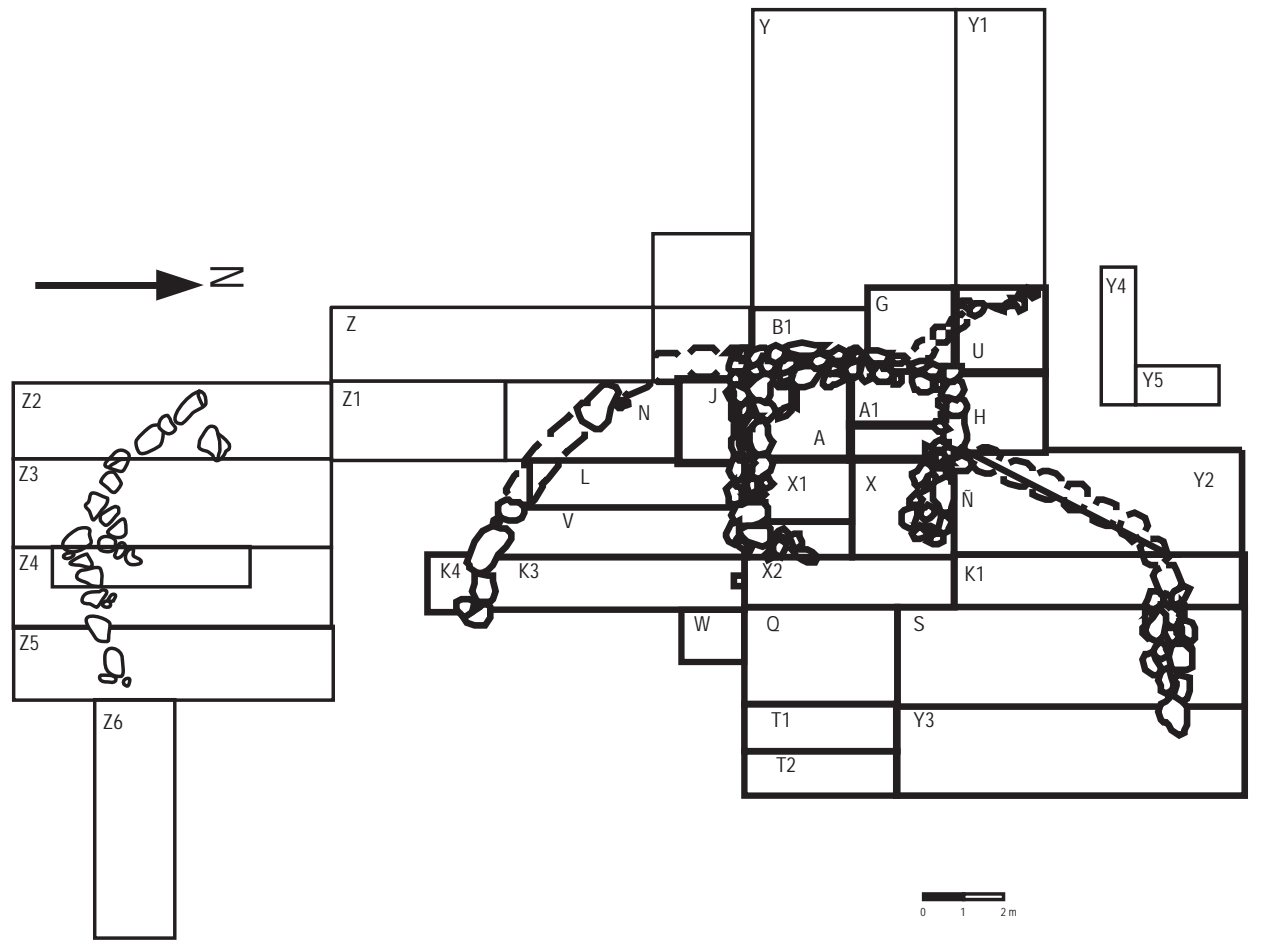

Figura 6. Distribución de las unidades de excavación, Ancosh Punta (PAn 5-5). 
distinguido el muro del lado este que cerraría la forma rectangular de la estructura, por lo que mejor se asemeja a la forma de una $U$ abierta al este. Las dimensiones de la estructura son de 3.4 x 4 m. Un pequeño fogón circular fue hallado en la esquina sudoeste adosado a la estructura, y se caracteriza por tener lajas puestas en canto asociado a un área con lentes de carbón y fragmentos cerámicos. El sedimento del piso de la habitación tuvo coloración gris oscuro que se repartió por toda el área de la estructura, yendo incluso a sus exteriores. Probablemente fue producido por la descomposición orgánica de los alimentos consumidos. Este sedimento de $16 \mathrm{~cm}$ de grosor fue excavado horizontalmente (132 metros cuadrados), obteniéndose una considerable cantidad de fragmentos cerámicos diagnósticos de distintas formas y decorados. También fue posible encontrar una gran cantidad de lascas, algunas puntas de obsidiana y puntas pulidas de pizarra y lutita en áreas específicas de la habitación que demostrarían cierto repartimiento preferencial de elementos y actividades en contextos fijos. Se encontraron muy pocos restos de huesos de animales, lo cual puede explicarse por la naturaleza abierta del sitio y la debilidad del suelo expuesto a permamentes lluvias y factores climáticos diversos que impidieron la conservación de restos óseos.

La forma rectangular de la habitación con un lado abierto debió haber tenido un techado de paja rellenado con ichu y sostenido por una estructura de palos, a manera de astiales, lo que adicionó mayor espacio exterior en la habitación. En el piso exterior este se observó una laja con una hendidura circular. Probablemente fue un hoyo de poste. Esta misma forma de construcción rectangular con un lado abierto fue empleada por los Inkas. Se encuentra distribuida en lugares altos y fríos de la zona del Cuzco. Gasparini y Margolies (1980:169) sugirieron su posible uso temporal y función diaria como centro de trabajo. Sapp (comunicación personal 2003), ha advertido esta misma forma constructiva en Macchu Picchu, en una zona dedicada para artesanos. Valcárcel denominó a este tipo de estructura masma (Gasparini y Margolies op. cit.). La correlación a sitios Inka concuerda perfectamente con la hipótesis de Ancosh Punta como vivienda temporal de pastores/cazadores para administrar el ganado y manufacturar puntas de proyectil.

\section{La Cerámica de Ancosh Punta}

El análisis cerámico se concentró en una cantidad de 1,030 fragmentos que constituye una muestra de $78.2 \%$ del total de fragmentería. En términos generales la estratigrafía del sitio no presentó diferencias. Era un sólo estrato que, por fines metodológicos se separó por niveles arbitrarios pero, el estudio ha revelado que estamos hablando de un solo gran momento o una ocupación continua del área.

\section{Estilo Ancosh/Cotojirca IV 650-950 AD}

Es una vajilla esencialmente doméstica que sigue ciertos patrones decadentes de la cultura Recuay. Existe una mayor incidencia de vasijas abiertas (Fig. 7); platos y cuencos achatados cuyos diámetros varían entre 18 y 25 cm. Están decorados al lado interior con bandas rojas oscuras (2.5 YR3/2, código de color Munsell). En algu-

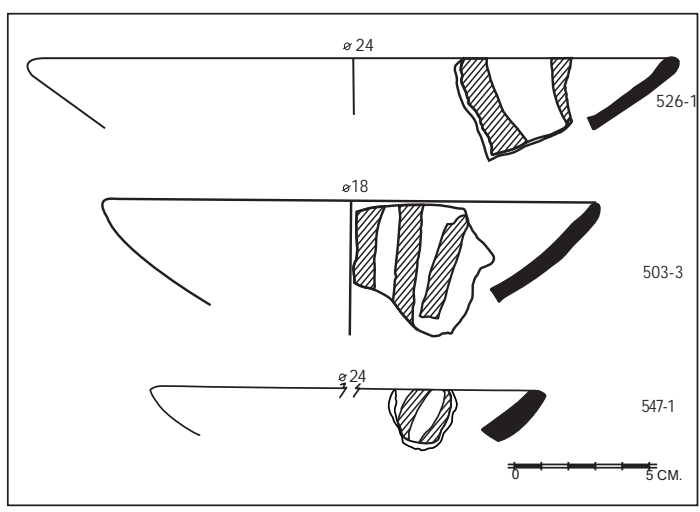

Figura 7. Cerámica de Ancosh Punta. Vasijas abiertas con decoración lineal pintada en rojo. 
nas ocasiones la banda es vertical color negro o marrón oscuro. Los boles o tazones son técnicamente mejor manufacturados y se asocian a la vajilla Recuay de la fase local Cotojirca III. Tienen pintura decorativa exterior rojiza. Los labios son adelgazados con filos redondos. El diámetro regular es de $22 \mathrm{~cm}$ y su altura promedio de $8 \mathrm{~cm}$. Las ollas tienen bordes evertidos con labios redondos. Poseen un fuerte punto de inflexión y presumiblemente tuvieron un cuerpo globular algo profundo. Destacable es la decoración que presenta; punteados circulares localizados entre el cuello/cuerpo (Fig. 8, 533-4).

Los diámetros de jarras van entre 29 y 27 $\mathrm{cm}$, indicando de grandes y altas vasijas cerradas con bordes evertidos que suavemente descienden a cuellos altos y rectos muy parecidos a las jarras modernas. Hay jarras más pequeñas de 13 a $17 \mathrm{~cm}$ de diámetro y cuellos de $5 \mathrm{~cm}$ de alto (Fig. 9). Un tipo de jarra se da con asas laterales localizadas entre el borde y parte alta del cuerpo (Fig. 9a). Sin embargo, asas planas más comunes se encuentran en el punto máximo de tangente vertical del cuerpo. Los cántaros se diferencian de las jarras por los cuellos más altos $(6-7 \mathrm{~cm})$ y por la inclinación de los bordes que no son tan evertidos. Una variante se caracteriza por tener un cuello compuesto convexo (Fig. 10a). Asimismo, portan elementos decorativos en forma de punteados en el área convexa del cuello y en el punto de intersección cuello/cuerpo. Consisten de punteados en líneas horizontales distribuidas homogéneamente y protuberancias rellenadas con puntos sobre una base alisada de color naranja pálido (Fig. 11). Entre los objetos cerámicos de Ancosh Punta destaca el hallazgo de una cabeza de figurina modelada escultóricamente (Fig. 12). Se trata de un personaje con turbante en la cabeza que tiene largas tiras en la parte posterior. Debajo del mentón tiene modelado un collar ancho con líneas incisas. Otro elemento común entre los hallazgos se constituyen los piruros; discos de cerámica con agujero cen- tral. Los piruros varían en tamaño desde los 5-2.5 $\mathrm{cm}$. Por último, se tiene cucharas en arcilla caolín blanca. Son sólo dos casos en que se han hallado fragmentadas. Una presenta decoración en pintura roja tanto en el mango como en el contenedor. Es claro que éstas cucharas son indicadores de presencia cultural Recuay, pues en el sitio Balcón de Judas excavado por S. Wegner (comunicación personal, 1999) encontró éste tipo de cucharas datándolas al Período Intermedio Temprano.

\section{Distribución de Vasijas en la Estructura tipo Masma}

La distribución de unidades de excavación al interior y exterior de la estructura habitacional, así como, el control por niveles arbitrarios de un

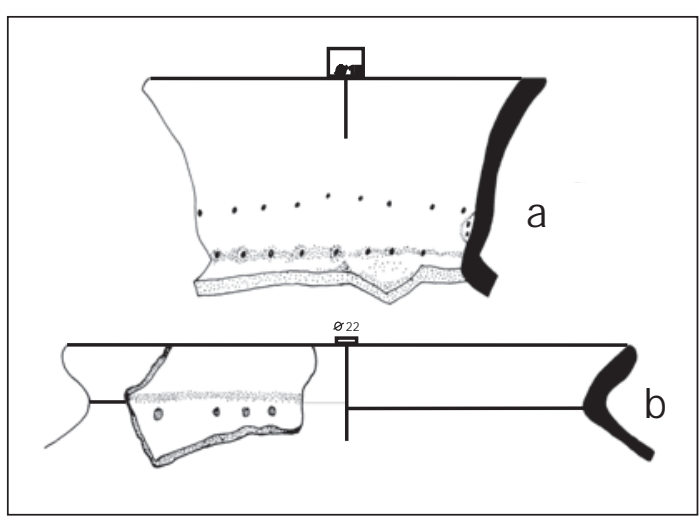

Figura 8. Cerámica de Ancosh Punta. Jarra y cántaro con decoración punteada.

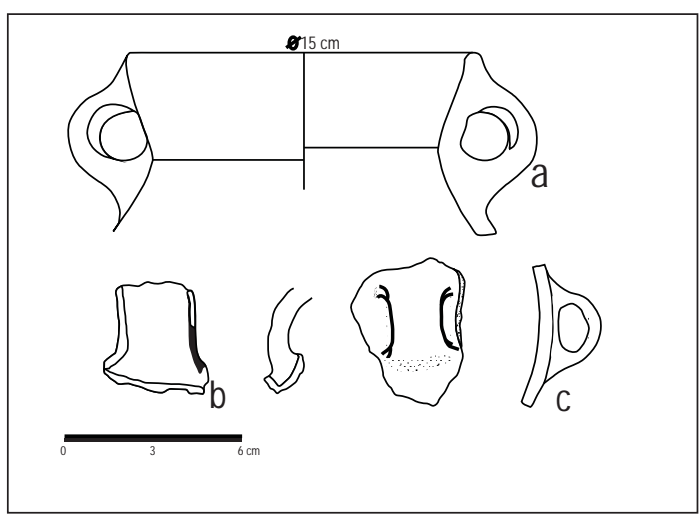

Figura 9. Ancosh Punta. Jarras con asas laterales. 

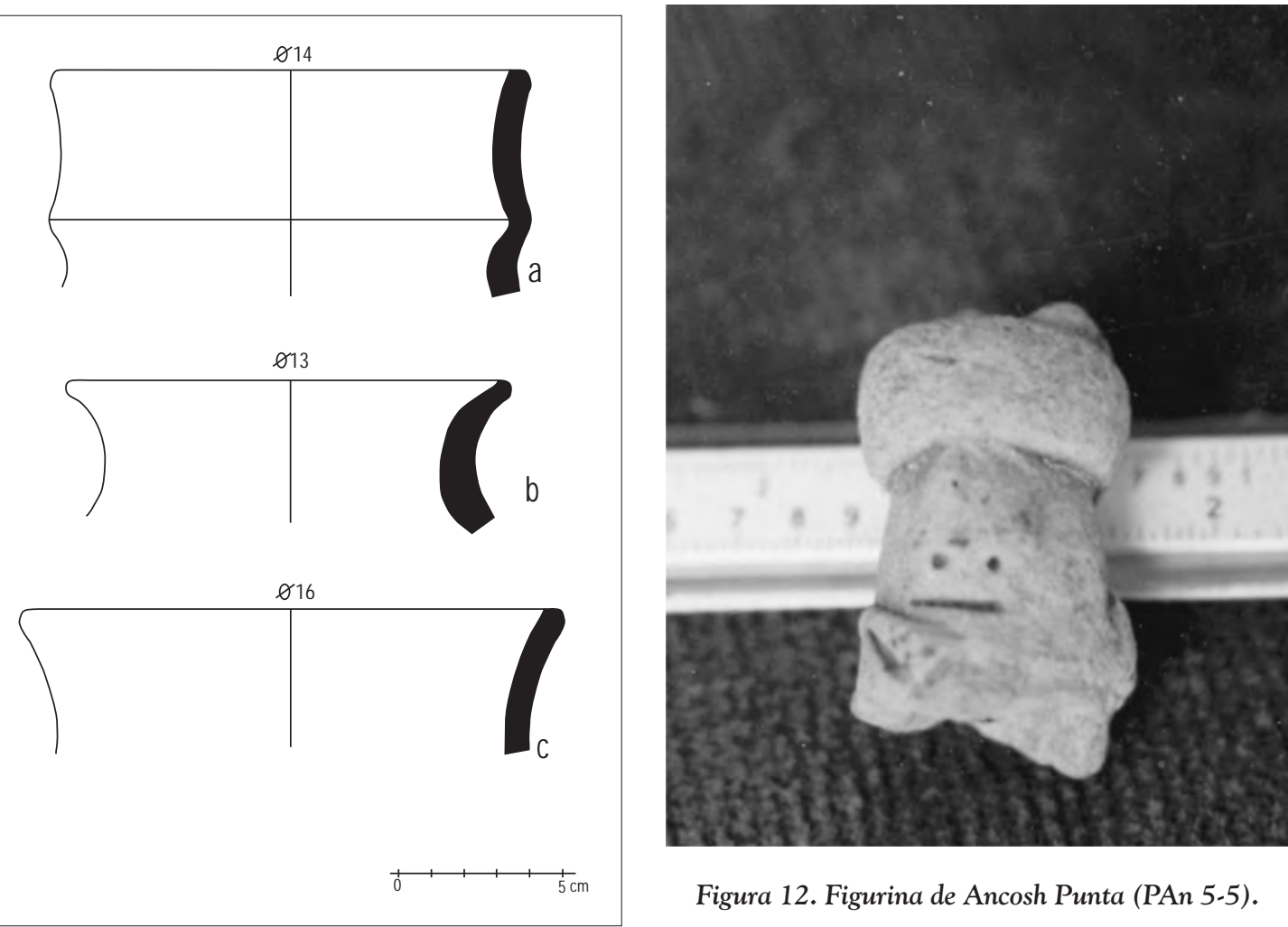

Figura 12. Figurina de Ancosh Punta (PAn 5-5).

Figura 10. Ancosh Punta. Jarras con cuello compuesto convexo
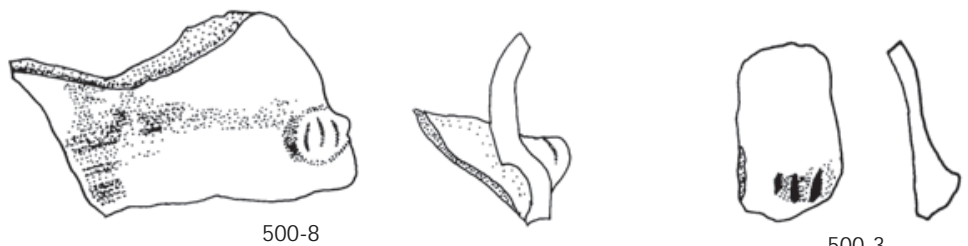

$500-3$
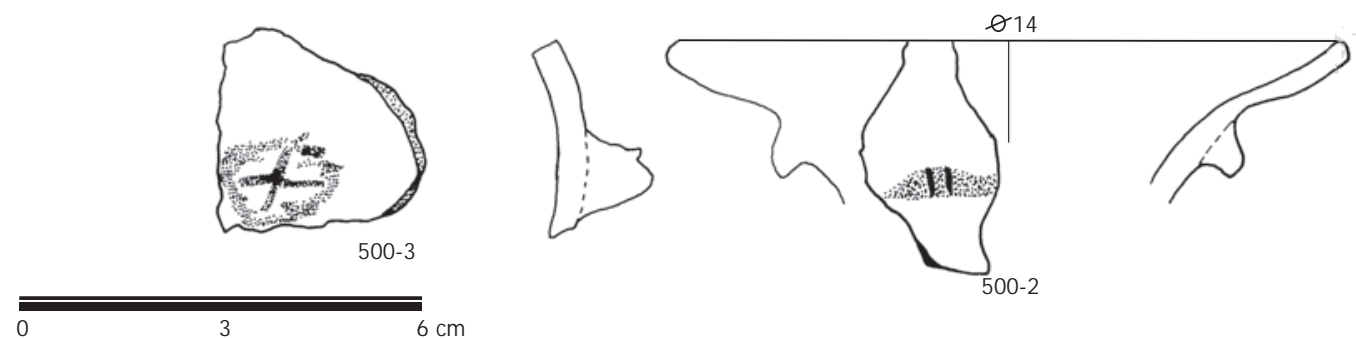

Figura 11. Cerámica tardía de Ancosh Punta. Aplicados con incisiones y decoración plástica. 
sólo estrato ocupacional permitió establecer un patrón u ordenamiento de vasijas ya sea por efecto de comportamiento humano deliberado frente a su hábitat (deposición cultural) o en todo caso de un sistema sin orden alterado por factores ambientales (Schiffer 1987:17), donde los desperdicios en este caso de vasijas rotas usadas son descartadas en varios lugares del recinto sin ninguna preferencia espacial. El análisis se ha dividido en 5 sectores.

\section{Tabla 1: Distribución de Unidades Analizadas de Ancosh Punta (PAn 5-5)}

\begin{tabular}{|l|l|}
\hline AREAS DE LA & \\
HABITACIÓN & UNIDADES \\
\hline 1. Interior & $\mathrm{A}, \mathrm{A}^{\prime}, \mathrm{I}, \mathrm{I}$ \\
\hline 2. Exterior Este & $\mathrm{K} 2, \mathrm{~T} 1, \mathrm{~T} 2$ \\
\hline 3. Exterior Oeste & $\mathrm{B}, \mathrm{B} '$ \\
\hline 4. Exterior Sur & $\mathrm{L}, \mathrm{J}, \mathrm{K} 4, \mathrm{~K} 3, \mathrm{~N}, \mathrm{~V}, \mathrm{~W}$ \\
\hline 5. Exterior Norte & $\mathrm{U}, \mathrm{H}, \mathrm{K} 1, \mathrm{~S}$ \\
\hline
\end{tabular}

En el interior de la habitación el número de vasijas abiertas (platos y cuencos) supera la utilización de vasijas cerradas (ollas, jarras, cántaros). La mayor intensidad se da en el nivel B (cuadro 1b) con una homogénea utilización del espacio. Mientras que el exterior Este se encuentra una mayor frecuencia de jarras y platos en el nivel $\mathrm{B}$ para luego en el $\mathrm{C}$ tener una equitativa muestra de vasijas abiertas regularizándose con la norma de mayor uso de éstas. Sin embargo, en el exterior Oeste en el último nivel casi al final del estéril continúa la población de cuencos. Este caso sólo se da en el exterior oeste. Asimismo, de esta zona proviene una escasa cantidad de restos óseos quemados de mamíferos que no han podido ser determinada su especie por encontrarse muy fragmentados (Rofes 1999).

El exterior Sur las barras de la tabla 1a muestran un homogéneo comportamiento de vasijas abiertas en el nivel superficial. Es la mayor concentración de material para este nivel.
El exterior Norte de la habitación ha sido utilizado con menor intensidad que otras áreas. La distribución de vasijas en el exterior norte mantiene un comportamiento más regular aunque siempre los platos y cuencos fueron más.

\section{Los artefactos líticos de Ancosh Punta}

El análisis del material lítico y dispersión del debitage fue realizado por Claudia Grimaldo (1999). Se contabilizaron 17 puntas de proyectil, 8 preformas y 52 artefactos modificados sobre lascas que contrastan fuertemente con la cantidad de desechos de talla (debitage) y lascas que en total sumaron 2,257 ítems (ver Tabla 2). Las puntas y herramientas líticas como cuchillos, raspadores, perforadores y puntas pulidas fueron talladas en el mismo sitio evidenciado por su contraparte en el debitage. Existe una mayor recurrencia de puntas pulidas de lutita (5) y puntas talladas de obsidiana (5), mientras que el resto estuvo compuesto de dacita, arenisca cuarzosa y jaspe moteada. Las diferentes rocas utilizadas en la manufactura de puntas y su debitage tienen procedencia geológica local. Sólo la obsidiana ha sido importada de fuentes alejadas no locales. No obstante, Grimaldo (ibid.) afirma que un tipo de obsidiana no translúcida puede provenir de una cantera local. Las puntas de obsidiana son de dos clases; una tiene 41 a $60 \mathrm{~mm}$ de largo con base recta y retoque a presión (Fig. 14). La otra es pequeña de forma triangular con base ligeramente cóncava de bordes laterales subrectilíneo cuyo largo es de $40 \mathrm{~mm}$ (Fig. 14b). Otras puntas con la misma forma triangular pero en arenisca cuarzosa también fueron hallados. Además, dos pequeños fragmentos de lascas de obsidiana retocados en ambos lados pueden ser buriles y lascas unifaces con probable evidencia de uso. Complementan la muestra, las puntas bifaciales pulidas de lutita las cuales estaban asociadas a puntas talladas (Fig. 14c). Estas tienen $45 \mathrm{~mm}$ de largo, base plana y curva con retoque o bisel rebajado. Debido a la limitada cantidad de 

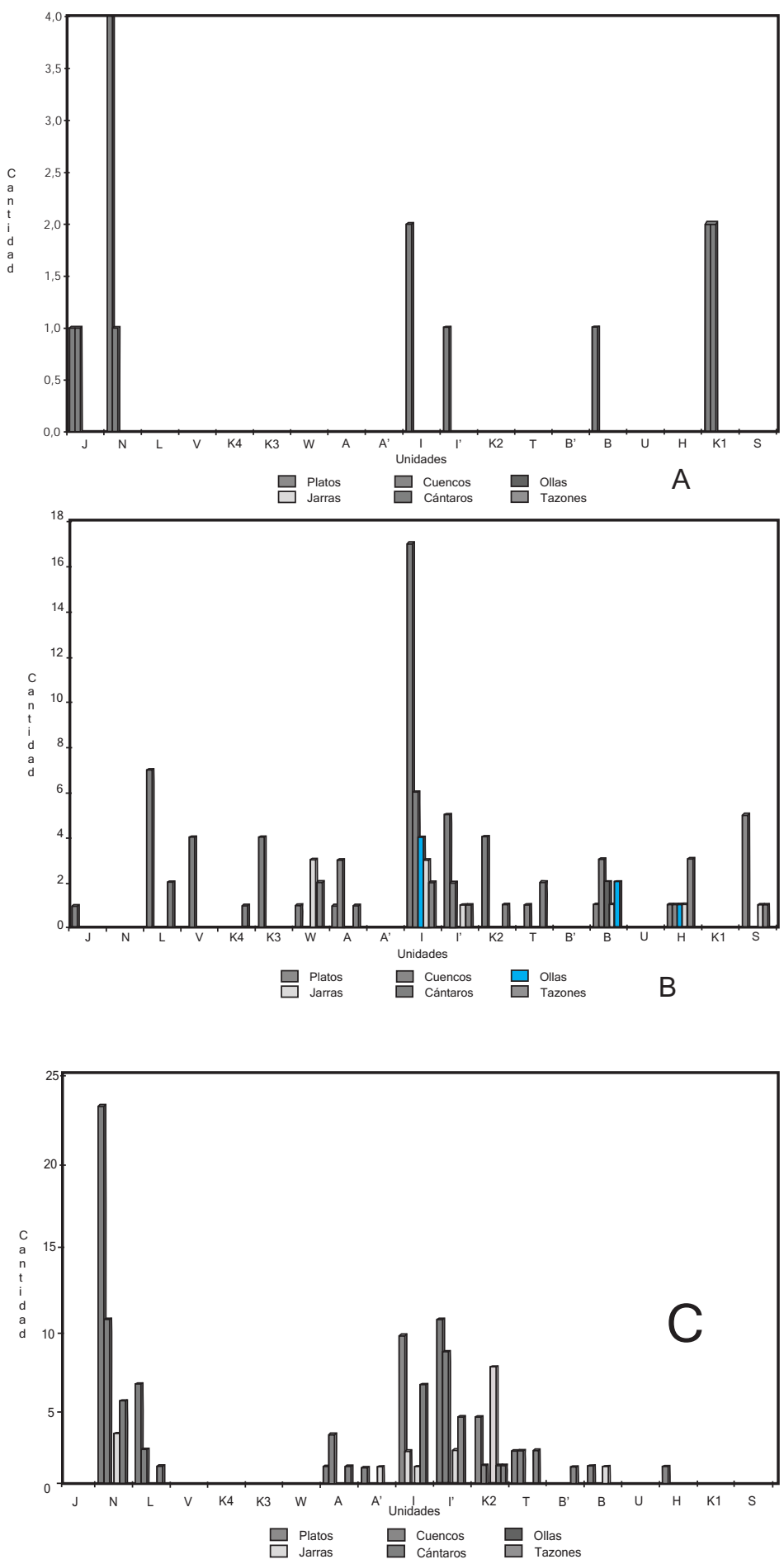

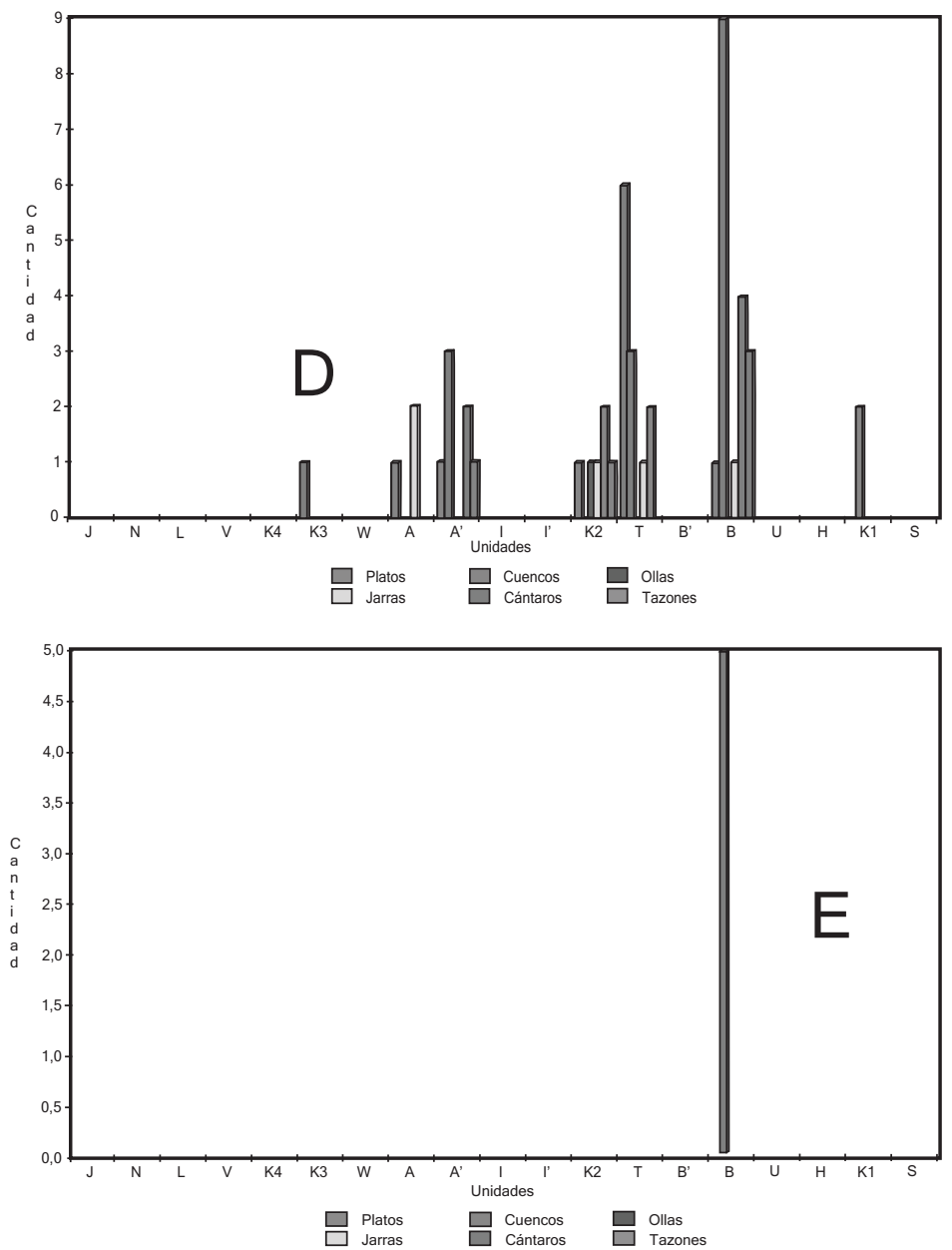

Figura 13. Ancosh Punta (PAn 5-5). Tabulación de barras. Cantidad de formas cerámicas distribuida horizontalmente y por niveles de excavación. A. Nivel superficial de Estrato 1. B. Nivel A. C. Nivel B. D. Nivel 1C. E. Nivel 1D.

debitage de obsidiana, sólo actividades que implican retoque y acabado final de las puntas se desarrollaron en el sitio.

Dispersión del debitage en la estructura tipo Masma

El comportamiento de la dispersión del debitage tiene semejanzas con la distribución de la cerámica doméstica dentro de la habitación. Sin embargo, la mayor concentración siempre se dio en los exteriores del frontis este, es decir en la zona abierta de la estructura tipo masma donde individuos estuvieron trabajando en la preparación y manufactura de puntas. Las densidades y frecuencia del debitage aparecen claramente en la secuencia de la figura 16, donde en los niveles B y C las cantidades son bastante elevadas, siendo los más intensos niveles de uso de la habitación.

\section{Muestra radiocarbónica}

El carbón de donde viene el fechado radiocarbónico de 690-980 AD, estuvo adherido a la pared de un fragmento cerámico utilitario. 

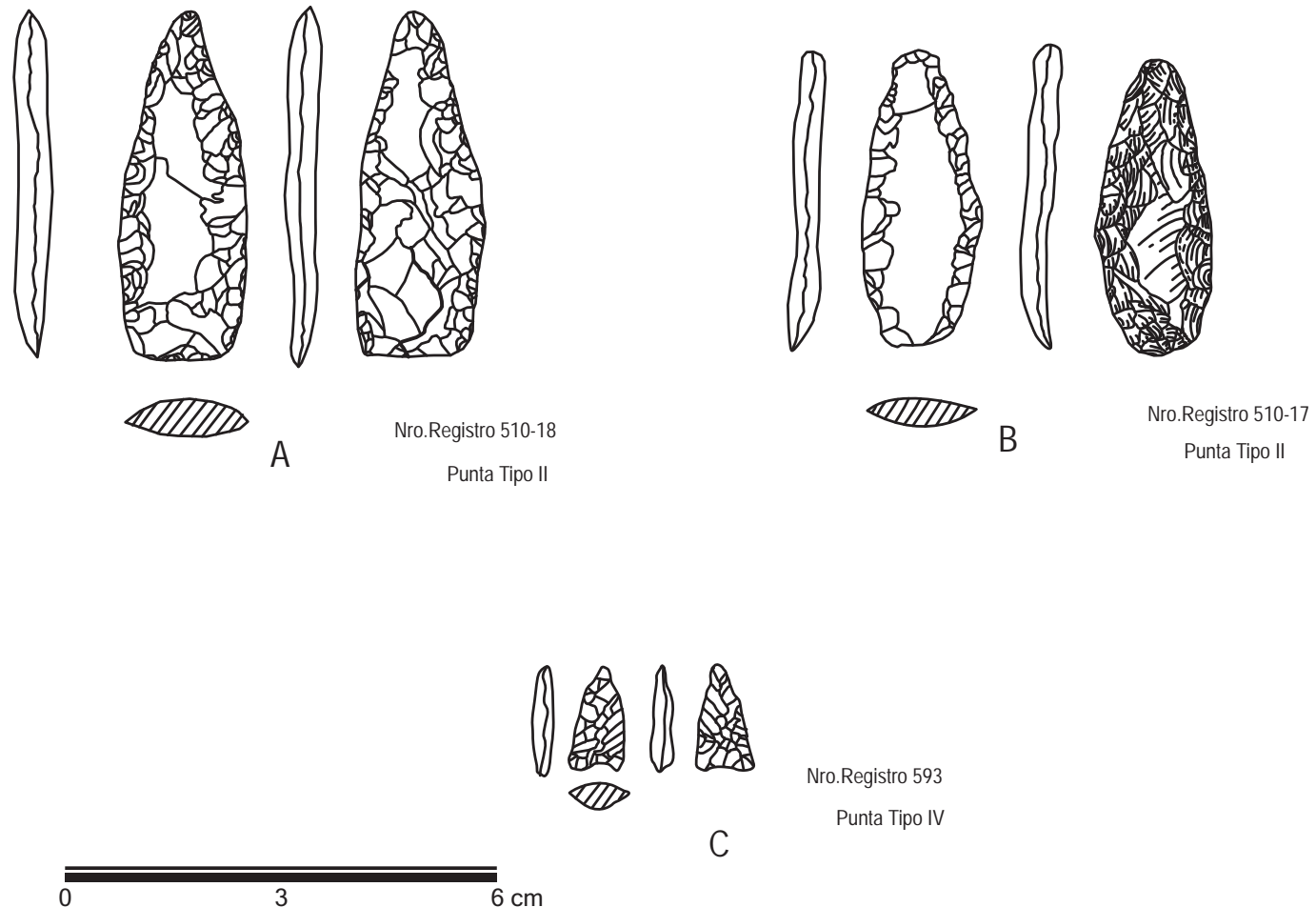

Figura 14. Material lítico de Ancosh Punta. Puntas de obsidiana.
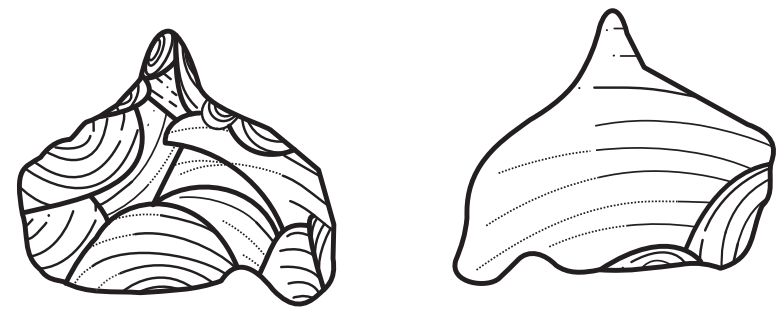

A

Util sobre lasca (perforador)

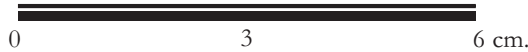

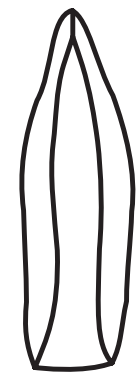

साD

B

Nro. Registro 400-7

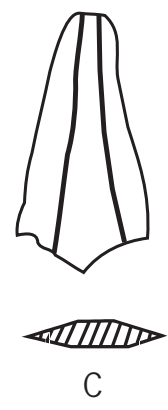

Nro. Registro 512-1

Figura 15. Material lítico de Ancosh Punta. Perforador y puntas pulidas. 


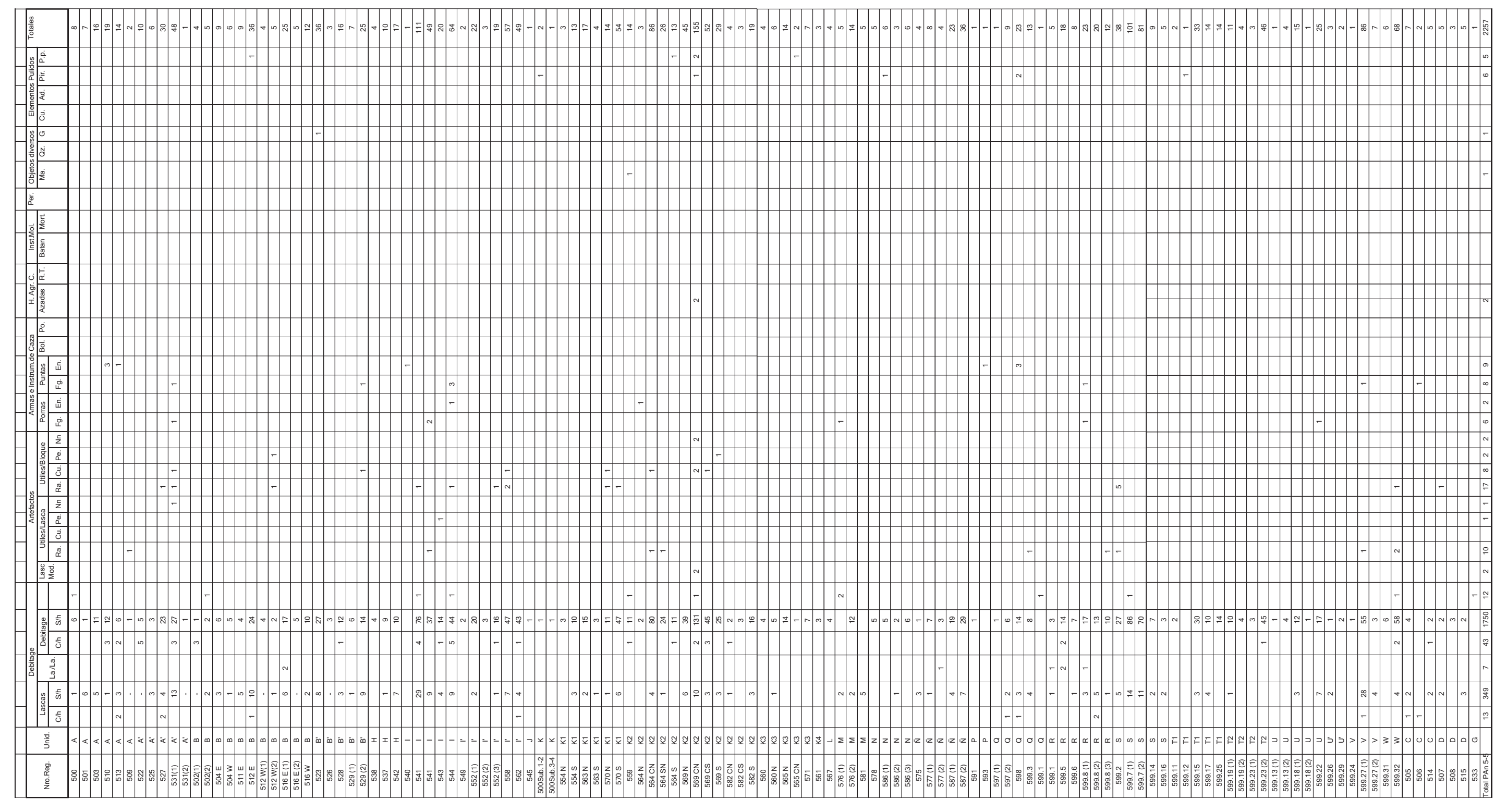



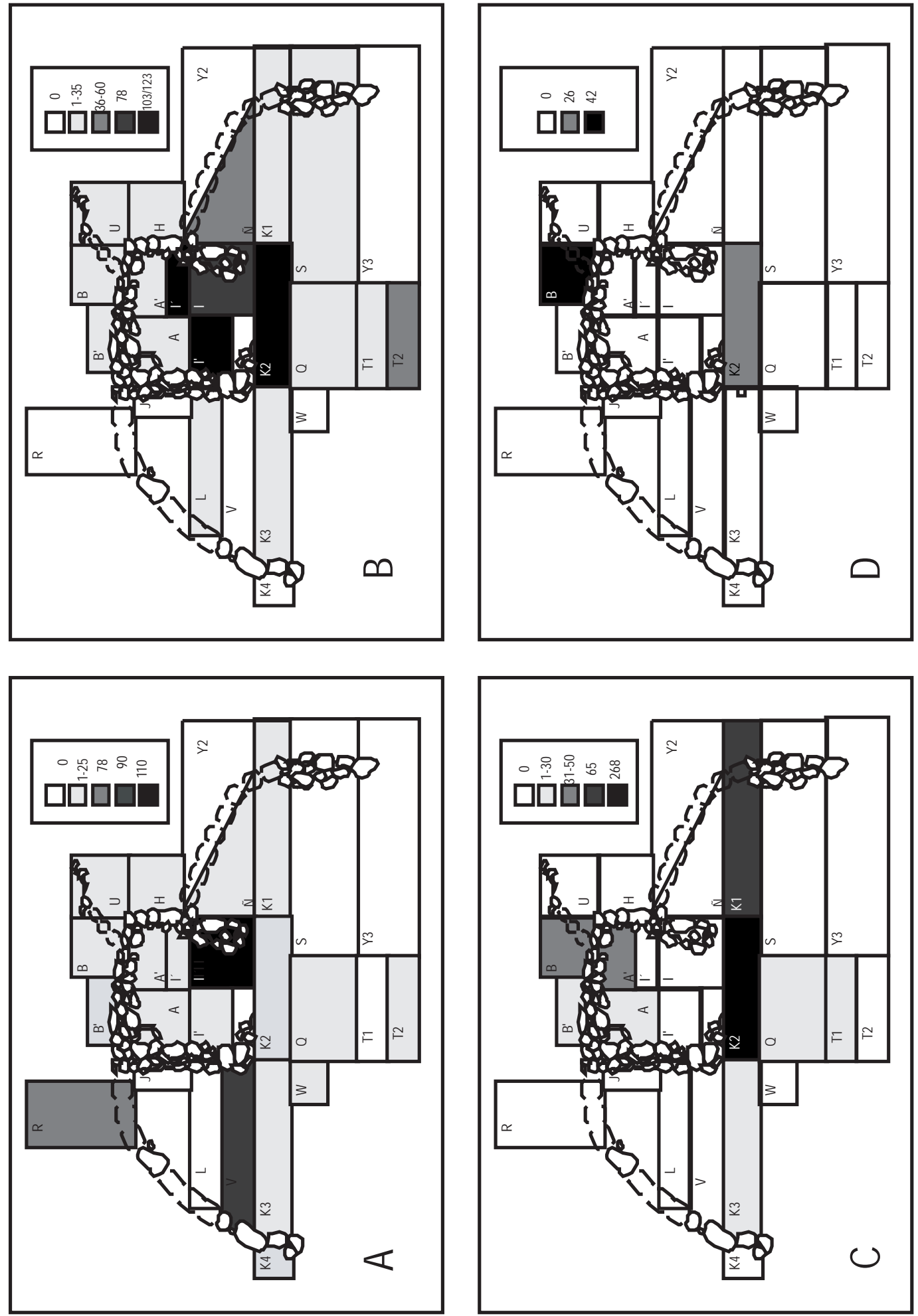
Corresponde a la Unidad Z2 localizada en el exterior sur de la habitación y asociada al muro o alineación de pesadas rocas que conformaron un corral antiguo. Corresponde a la capa 1 nivel B donde existió la mayor concentración e intensidad de la ocupación. Se asocia a fragmentos rústicos o vajilla de uso común llana sin decoración, destacando las formas abiertas de cuencos y platos. La unidad donde provino la muestra, pese a estar localizada a 7 metros de la habitación, aún tenía una fuerte concentración de material cerámico a manera de basural, donde también habían desechos de talla y algunas minúsculas lascas de obsidiana. Interesantemente, la muestra estuvo asociada sólo a platos y cuencos sin encontrarse ningún elemento estampado en la decoración de vasijas cerradas. El único fragmento diagnóstico detectado, proviene de la unidad vecina Z1 donde hubo un fragmento de base trípode roto y un borde de olla globular con refuerzo exterior.

\section{Llaca Amá Caca (PAn 5-58)}

El lugar consiste en una serie de prominencias rocosas naturales que dan frente a la Cordillera Blanca sobre los 4,043 metros de elevación dentro del área de operaciones de la mina Pierina (Fig. 17). Las rocas forman varios desniveles, en uno de éstos, en el sector IV, se encuentra un abrigo rocoso que ocupa un área de 250 $\mathrm{m} 2$ aproximadamente con densidades importantes de material arqueológico. Se indica que en otros sectores del sitio se encontraron evidencias de estructuras Recuay, además de restos de corrales contemporáneos abandonados. En el mismo abrigo se tienen varias ocupaciones culturales; desde precerámico hasta Inka inclusive, habiéndose sido disturbado la original secuencia cultural estratigráfica por la instalación de tumbas Inkaicas y del período Intermedio Tardío. El sector II también explorado, estuvo conformado por otro abrigo de menor tamaño delimitando un área de 56 metros cuadrados. La excavación de sondeo en este sector, no mostró indicadores de estructuras arqueológicas pero sí se encontró un piso o sedimento carbonoso oscuro con elementos orgánicos asociados a fragmentos cerámicos y puntas de proyectil con pedúnculo. En este abrigo no había elementos relacionados a entierros u ofrendas dedicatorias por lo que suponía los estratos podían estar sin disturbar. La muestra de artefactos líticos analizada del sector II fue de 145 ítems. Los tipos de rocas utilizados en la manufactura de puntas y debitage han sido jaspe, lutita, obsidiana, arenisca cuarzosa, riolita (Grimaldo 1999). De éstos, solamente 7 fueron puntas de proyectil cuyas formas foliácea alargada y con pedúnculo son asociados a puntas pulidas y por lo tanto relativamente tardías. Restos de camélidos y cérvidos se presentaron quemados muy posiblemente consumidos en el lugar. Por otro lado, en el sector IV se definió un conjunto cerámico compuesto de platos y cuencos abiertos que exhiben las mismas características estilísticas con relación a Ancosh Punta (Fig. 18). Las formas decorativas apliqué y estampado circular pequeños $(4 \mathrm{~mm})$ en vasijas cerradas estuvieron asociadas a los platos. De ese mismo contexto (5839) compuesto por un sedimento negro carbonoso de la capa 2 se tuvieron 45 materiales líticos. Lascas mayormente de arenisca cuarzosa, 2 tuvieron huellas de uso, 1 punta pulida fragmentada en andesita de $66 \mathrm{~mm}$ de largo y $20 \mathrm{~mm}$ de ancho máximo (Fig. 19a, 5839c-48) y 2 puntas talladas bifaciales pedunculadas de $42 \mathrm{~mm}$ de largo en roca silstone (Fig. 20e y 21a 5839c-49 y $11,5839 c-50)$.

\section{Muestra radiocarbónica}

La muestra tomada para fechamiento absoluto proviene de la capa 2a del sector II (5841), consistente en un sedimento carbonoso oscuro con elementos orgánicos. Del mismo nivel caracterizado por una alta concentración de carbones y fogones se encontró restos de Phaseolus sp. (género de frijol), planta alimenticia cultiva- 


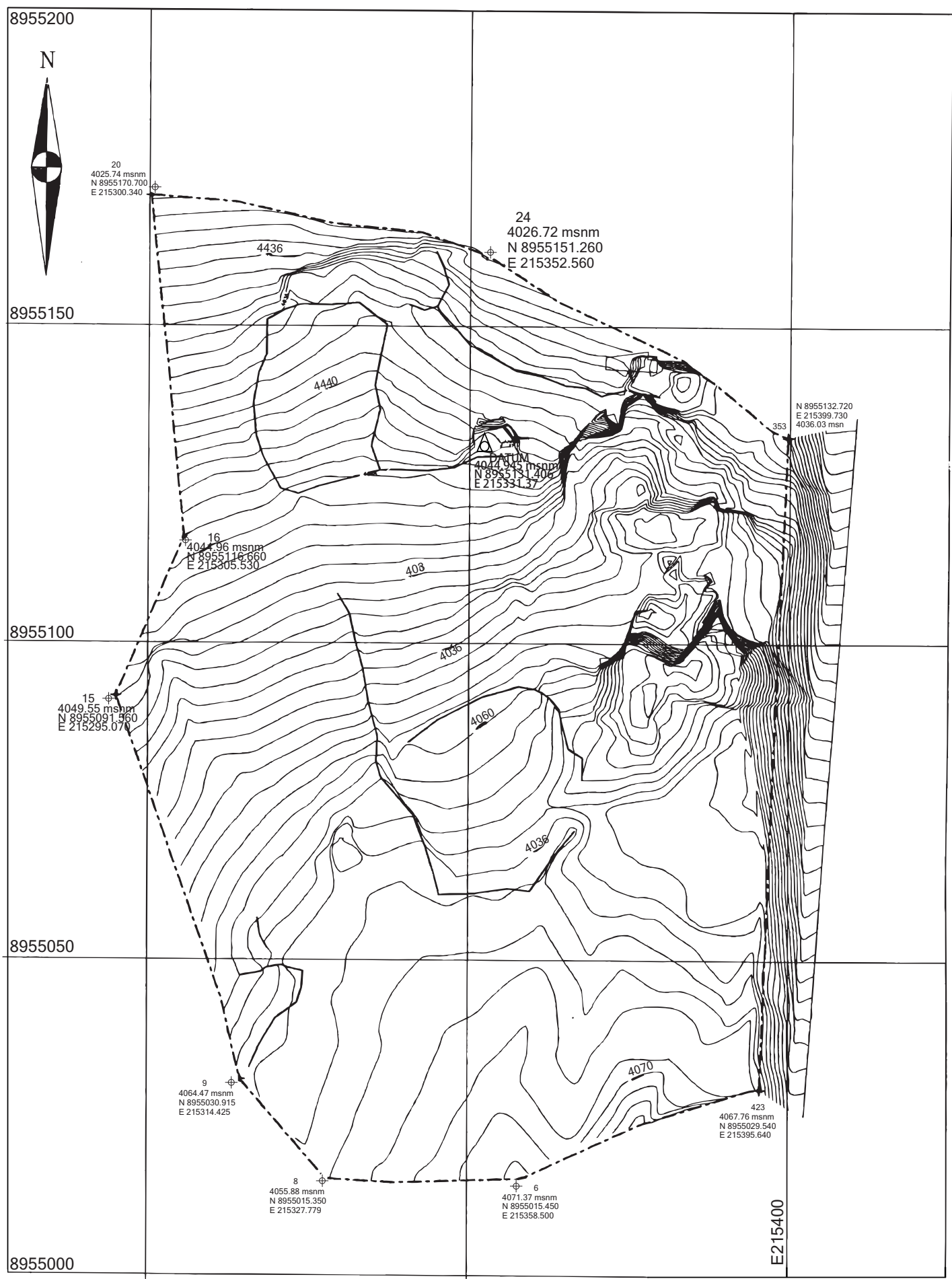

Figura 17. Plano de Llaca Amá Caca (PAn 5-58). 

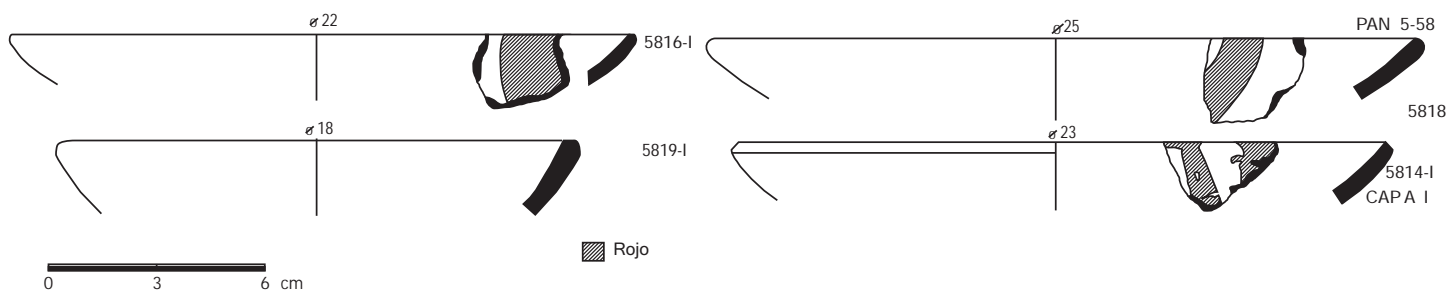

URA Rojo

Figura 18. Cerámica de Llaca Amá Caca (PAn 5-58)

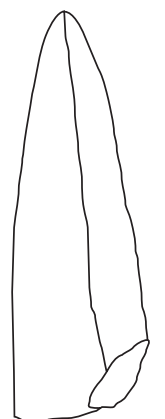

Sector IV Nro. Registro 5839c-48

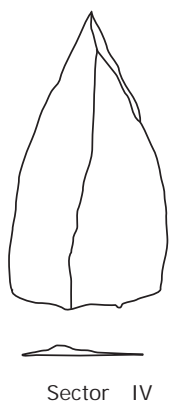

Nro. Registro 5862a-2
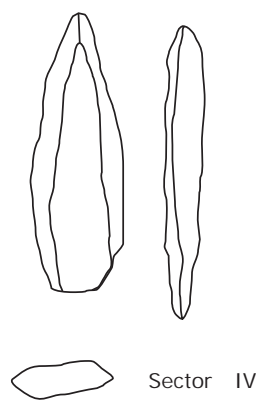

Nro. Registro 5852-10

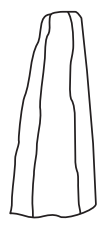

Sector IV

Nro. Registro 5835b-5
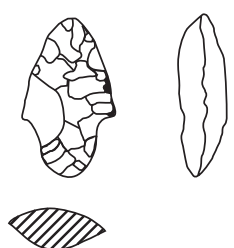

Nro. Registro 5846b-15
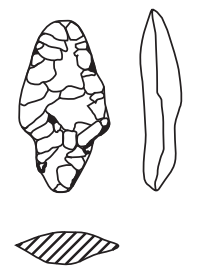

Nro. Registro 5870/2a-27

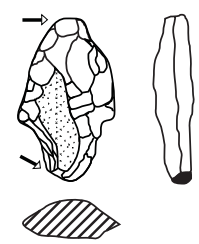

Nro. Registro 5870/2a-24

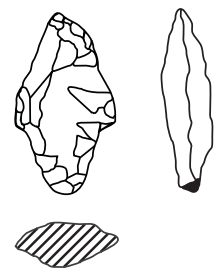

Nro. 5845/1b-6
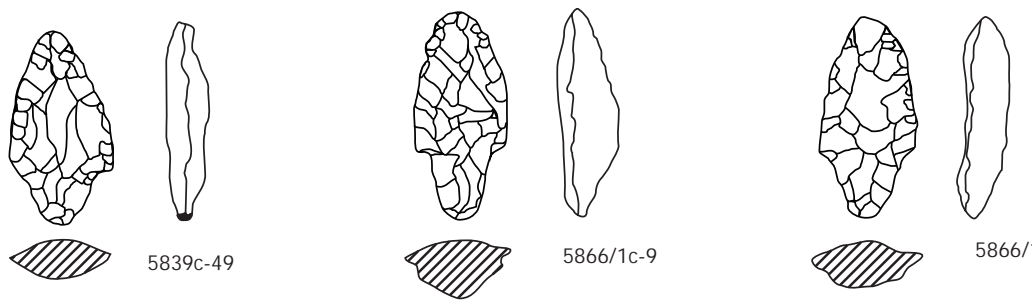

5866/1c-9

$5866 / 1 c-8$

\section{0}

$3 \quad 6 \mathrm{~cm}$

Figura 20. Llaca Amá Caca. Puntas bifaciales pedunculadas asociadas al nivel Horizonte Medio. 

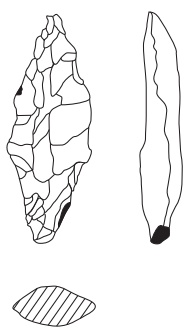

Nro. Registro 5839c-50

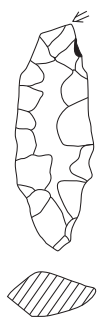

Nro. Registro 5870/2a-22
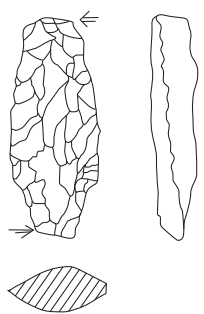

Nro. Registro 5838c-25

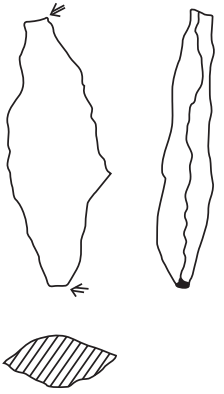

Nro. Registro 5870/2a-23

\section{$3 \quad 6 \mathrm{~cm}$}

Figura 21. Llaca Amá Caca. Puntas bifaciales pedunculadas asociadas al nivel Horizonte Medio.

\begin{tabular}{|c|c|c|c|c|c|c|c|c|c|}
\hline Sector & II & II & II & II & II & II & II & II & II \\
\hline Unidad & B-D & B-D & B-E & B-E & B-E & $\mathrm{B}-\mathrm{F}$ & C-G & $\mathrm{D}$ & $\mathrm{D}$ \\
\hline Capa & 2 & $2 \mathrm{~B}$ & 2 & $2 \mathrm{~B}$ & $2 \mathrm{C}$ & 2 & $2 \mathrm{~B}$ & $1 \mathrm{~B}$ & 2/R1 \\
\hline Litros & $\mathrm{D}$ & 1,6 & 0,5 & 1,5 & 1,4 & 0,7 & 2,5 & 1,1 & 1 \\
\hline Peso (grs.) & 640 & 151 & 390 & 137 & 150 & 690 & 231 & 120 & 380 \\
\hline Peso final (grs.) & Perd & 4,3 & 11,7 & 6,4 & 4,2 & 1,8 & 12,5 & 16,1 & 2,5 \\
\hline \multicolumn{10}{|l|}{$8^{\prime}$} \\
\hline Phaseolus sp. & & & & 1 & & & & & \\
\hline cf Galium & & & & & & & 1 & & \\
\hline Peso & & & & & & & 0 & & \\
\hline Carbones (núm.) & & 15 & 23 & 23 & 60 & & 157 & & 129 \\
\hline Peso & & 0,4 & 0,5 & 0,3 & 0,6 & & 2,3 & & 1,7 \\
\hline Hoja \#1 & & & & 2 & & & & & \\
\hline Coprolito de herbívoro & & & $\mathrm{P}$ & & & & & & \\
\hline \multicolumn{10}{|l|}{ Peso } \\
\hline Fruto, cáscara & & & & & 2 & & & & \\
\hline \multicolumn{10}{|l|}{$16^{\prime}$} \\
\hline cf Galium & & & & & 1 & & & & \\
\hline cf Phaseolus/Medicago & & & & 1 & & & & & \\
\hline \multicolumn{10}{|l|}{$50^{\prime}$} \\
\hline Labiatae & & 2 & & & 1 & & & & \\
\hline Scirpus & & 1 & & 1 & 1 & & & 7 & \\
\hline Cactacae\#1 & & & & & 1 & 1 & & & \\
\hline Eupthorbia & & & & & 1 & & & & \\
\hline Urocarpidium & & & & & 1 & & & & \\
\hline cf Eleocharis & & & & & & & & 1 & \\
\hline Carex & & & & & & & & 5 & \\
\hline Vervena & & & & & & & & 3 & \\
\hline Espécimen \#3 & & & & & & & & 1 & \\
\hline cf Medicago & & & & & & & & 5 & \\
\hline cf Lotus/Melilotus & & & & 1 & & & & 3 & \\
\hline cf Malvastrum & & & & & & & & 5 & \\
\hline Asteraceae\#1 & & & & & & & & 1 & \\
\hline Solanum spp. & & & & & & & & 6 & \\
\hline Plantago & & & & 1 & & & & & \\
\hline No identificado & & & & & 1 & & & 4 & \\
\hline
\end{tabular}

Tabla 3. Evolución por unidad del Sector II de los restos vegetales en Llaca Amá Caca (Tomado de Chevalier 1999). 
da y otras plantas como Scirpus, Chenopodium y Solanum spp (Tabla 3). Igualmente, pero en menor frecuencia que el sector IV, se hallaron restos faunísticos de camélidos y cervidos de distintas edades. Los huesos se encontraban quemados posiblemente consumidos. El fechado obtenido de 640-870 AD calibrado a dos sigma, fue tomado de un carbón vegetal proveniente de fogones.

Lamentablemente, los datos de Llaca Amá Caca debemos tomarlos de manera cauta debido a la profunda disturbación de la estratigrafía cultural. Es recurrente hallar en los abrigos rocosos del Callejón de Huaylas, un tipo de estratigrafía invertida donde debitage y puntas precerámicas pueden ser encontradas en los niveles iniciales mientras que en los niveles finales pueden encontrarse cerámica (Lynch 1967:781). Asimismo puede haber mixtura de materiales producto de la instalación de tumbas tardías que intruyeron pisos antiguos (Lynch 1971:143). El caso de Llaca Amá Caca es interesante por la sostenida ocupación de los abrigos a lo largo del tiempo por distintas sociedades; se pudo encontrar tipos cerámicos de todos los períodos culturales del Callejón de Huaylas. Esto indica la importancia del lugar tanto por finalidades de apropiación de recursos y hábitat como para desarrollos de rituales funerarios.

\section{Las chullpas de Yarcok (PAn 5-41)}

A una elevación de 3,784.506 msnm bajo el tajo abierto de la mina Pierina y en zona de vertiente se encuentra el lugar funerario (plano 6). El nombre del sitio proviene de un manantial cercano que proporciona agua para el actual poblado de Mareniyoc. Esta área de topografía abrupta y afloraciones rocosas de toba volcánica nunca fue cultivada. Las estructuras funerarias fueron construidas con la misma roca del lugar encontrándose mimetizadas en el terreno. Se encontraron 22 chullpas de forma rectangular con la entrada siempre dirigida al este. Las construccio- nes se encuentran agrupadas, hay un sector central que parece ser el más importante con un acondicionamiento especial de terrazas y pequeños cercos que demuestran su jerarquía frente a otras más comunes. Se encuentran distribuidas por toda la ladera rocosa y tienen por dimensiones promedio $5 \mathrm{~m}$ de largo x $3.0 \mathrm{~m}$ de ancho y 1.3 $\mathrm{m}$ de altura. La techumbre lo constituye grandes lajas a manera de vigas muy pesadas colocadas encima de los muros entre un relleno de barro y cascajo, muchas de éstas se han caído y removido por los últimos cataclismos. El paramento externo de las estructuras se compone de grandes rocas lisas de 0.80 - $1 \mathrm{~m}$ de altura promedio unido con argamasa amarilla en sus junturas y rellenado con piedras pequeñas con la técnica de pachillas (figura 2).

El estilo de tumbas Recuay que utilizan grandes peñas como techumbre, también está catalogado en el sitio (CH-12). Debió tener un rol secundario frente a las otras de forma rectangular. Se excavaron 3 chullpas (CH-12, $\mathrm{CH}-11$ y $\mathrm{CH}-8)$ elegidas por su mejor arquitectura expuesta.

La chullpa 11 (CH-11) fue la más grande y mejor conservada (figura 3). Se tuvieron dos hallazgos en la capa 2 (4120) al interior de la cámara funeraria, uno fue un ceramio escultórico de un personaje con sombrero de cuatro puntas con las manos hacia atrás (fotografía 3) y otro fue un cuenco llano (4120-1). Ambos estaban asociados a restos óseos humanos muy fragmentados. En cambio, en el exterior de la misma chullpa se hallaron 4 vasijas casi completas relacionadas a la entrada del edificio pues estaban dispuestas a ambos costados del acceso. Estas son: una vasija con asa estribo escultórica de un pelícano (lámina 12), un cantarito con representación impresa de un personaje flanqueado entre dos felinos vistos en perfil (Lámina 13, 4122-2) y dos cuencos fragmentados. Los hallazgos confirmaron la jerarquía de la chullpa debido a la mejor elaborada arquitectura en comparación a las 


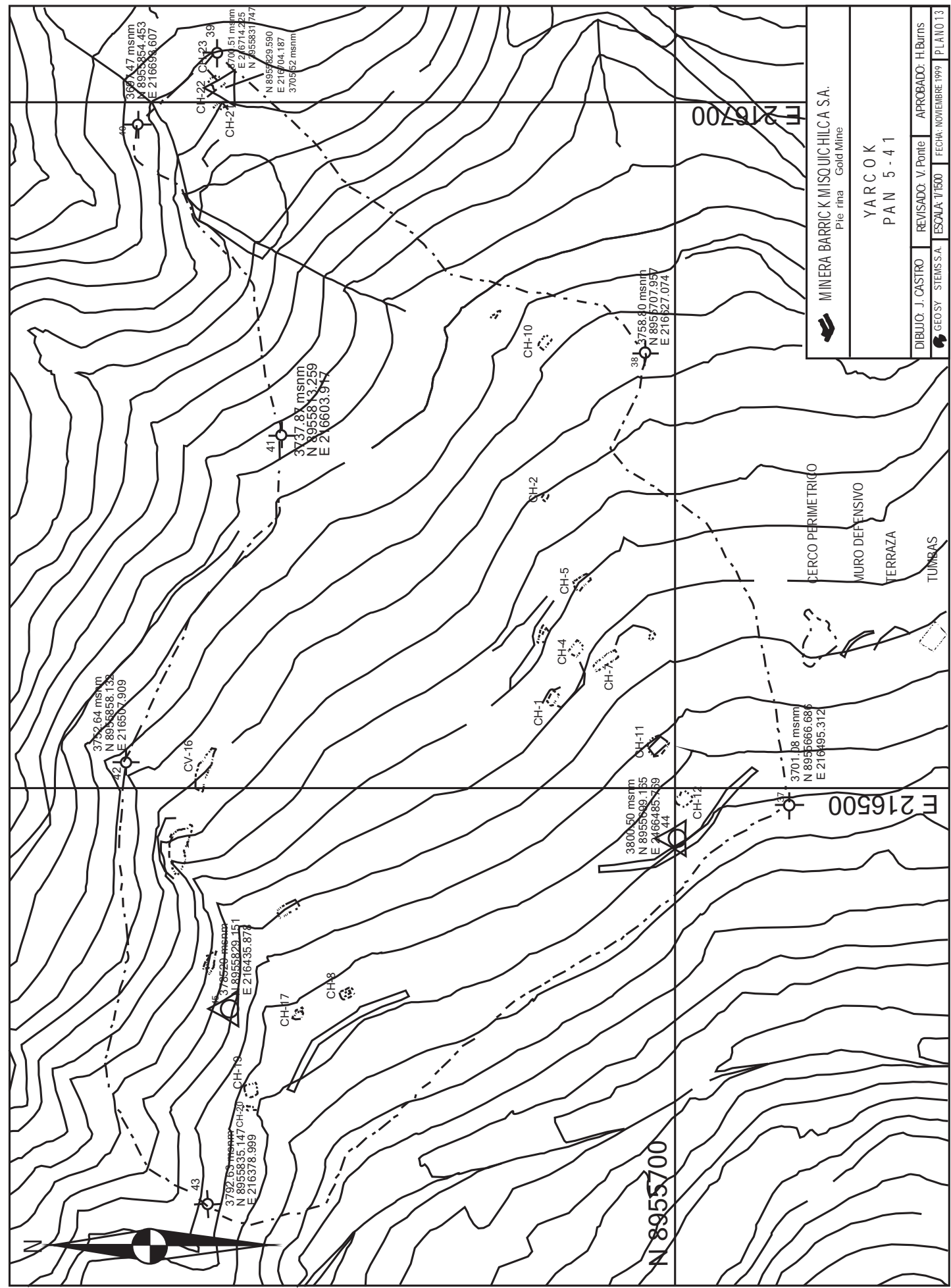

Figura 22. Plano del sitio Yarcok (PAn 5-41). 


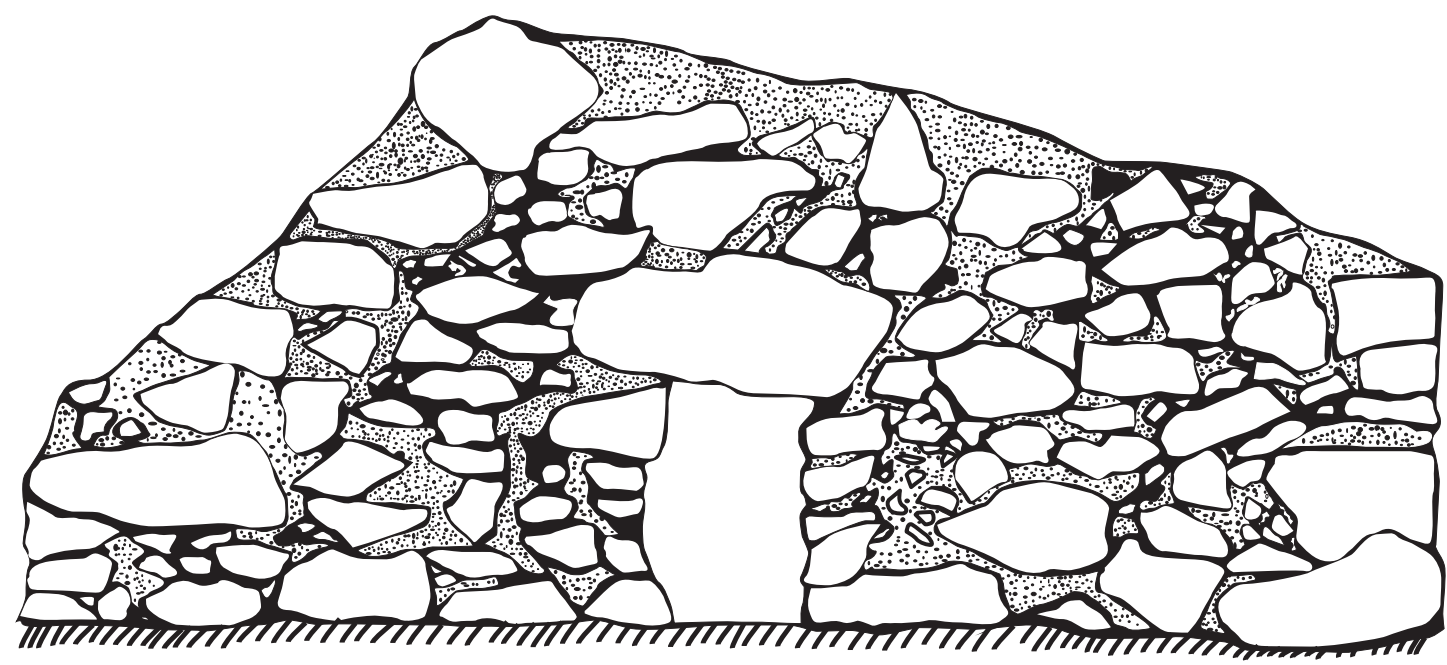

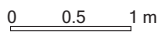

Figura 23. Yarcok (PAn 5-41). Fachada Este de la Chullpa 11.

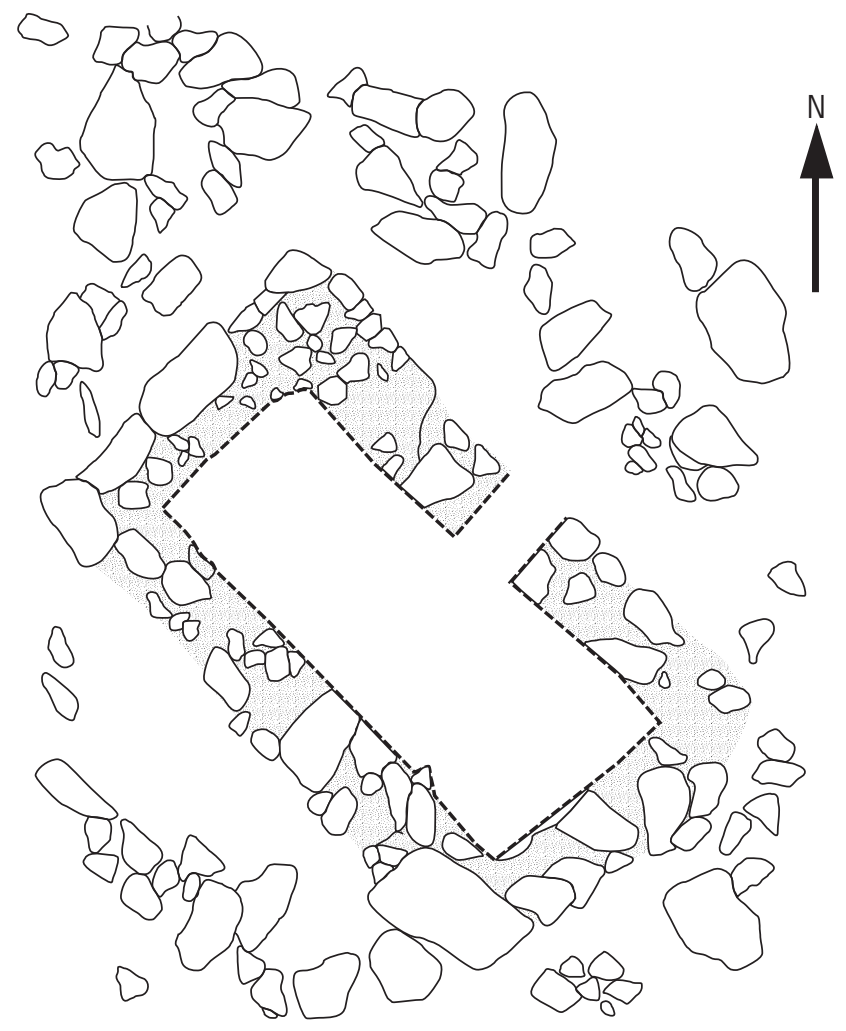

Figura 24. Yarcok (PAn 5-41). Dibujo de planta de la Chullpa 11. 


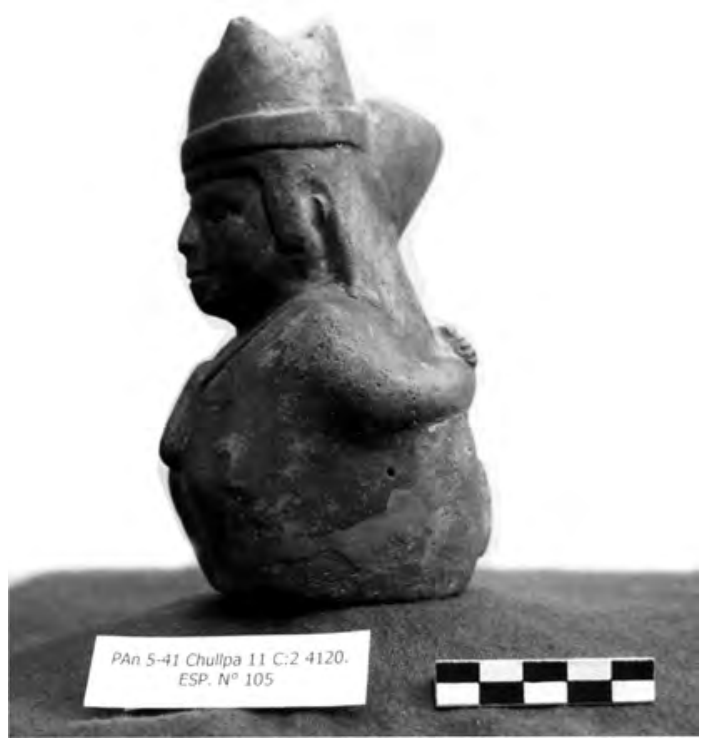

Figura 25. Personaje Wari con sombrero de cuatro puntas.

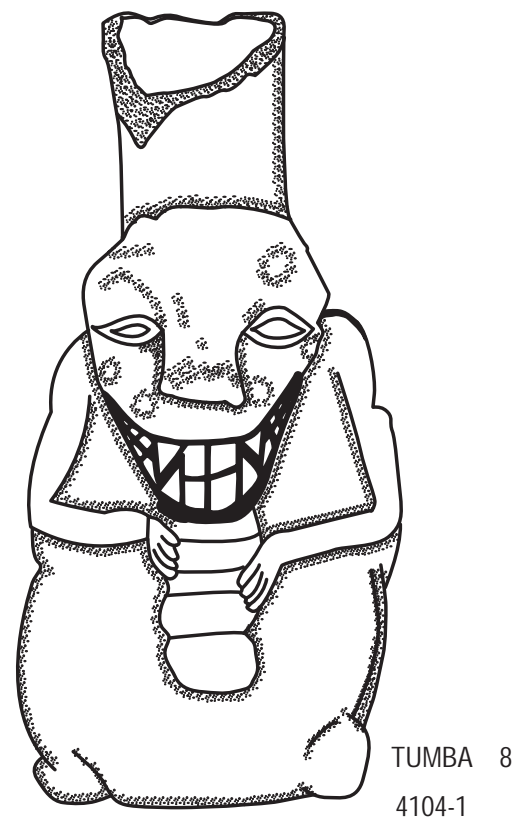

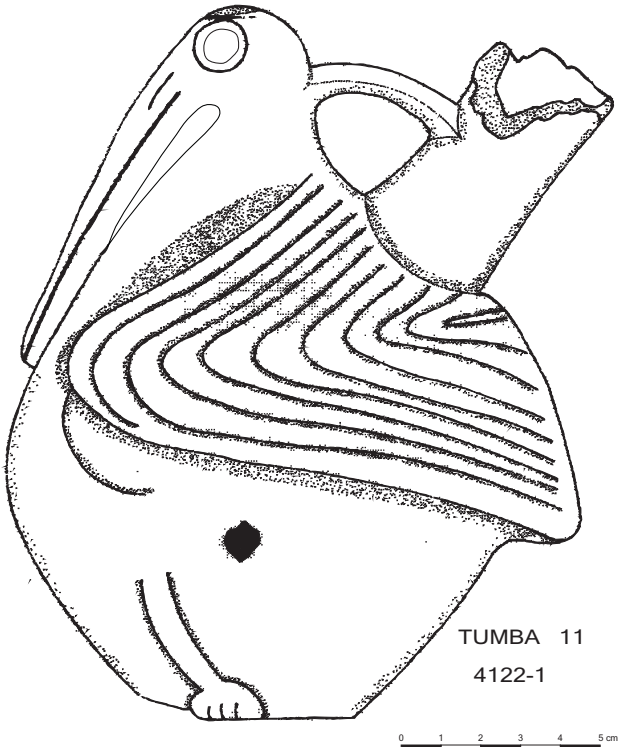

Figura 26. Yarcok (PAn 5-41) Cerámica entera. Asa puente modelado de pelícano.

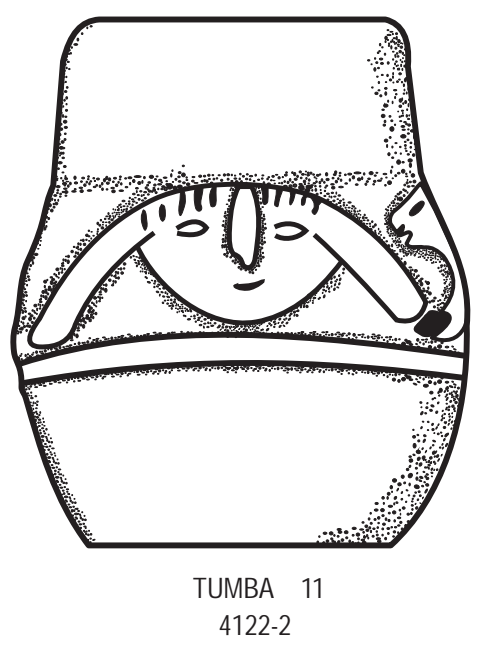

Figura 27. Cerámica entera de las chullpas de Yarcok. Ser zoomorfo con vaso en las manos (4104-1) y cántaro con decoración impresa (4122-2). 
demás. Un batán se encontraba también asociado en el exterior de la plataforma, probablemente usado en las ceremonias de renovación y culto a los muertos (Valdez et al 2000:390). La localización de los hallazgos en la puerta y siempre dirigidos hacia el este mirando la Cordillera Blanca, tienen connotación ritual referida al paso de la vida a la muerte en un marco natural controlado por dioses tutelares (apus) de las montañas.

La chullpa 8 (CH-8) tuvo las mismas características a la anterior hallándose en el interior de la cámara fragmentos cerámicos de una olla utilitaria asociados a restos óseos humanos muy frágiles sin poder inferir el número de individuos ni la posición de los cuerpos. Siempre en el acceso, se encontró una vasija modelada de un ser zoomorfo que sujeta un vaso entre sus manos (lámina 13, 4104-1). Mientras que la chullpa $12(\mathrm{CH}$ 12), la única diferente al resto, tenía planta semicircular conformada por tres muros de $0.80 \mathrm{~m}$ de altura y una gran peña de $3.8 \mathrm{~m}$ por $4.4 \mathrm{~m}$ como techumbre. Se encontraron pocos elementos diagnósticos tales como restos de un cuenco naranja fragmentado y cerámica llana no diagnóstica. No se hallaron restos humanos, pero sí una concentración de carbones y restos vegetales. De este último, plantas alimenticias como chenopodium y Solanacea (quinoa y papas) podrían ser inferidas aunque también existen variedades silvestres (Chevalier 1999). Sin embargo, la existencia de Scirpus puede indicar algún modo de enfardelamiento con juncos (tabla 4). Por el estilo diferente de esta tumba, debe ser Recuay pero muy decadente o tardío demostrándose cierta sumisión de la estructura frente a las chullpas rectangulares.

\section{Muestra Radiocarbónica}

El fechado radiocarbónico de 775-995 AD fue obtenido de una muestra de restos óseos

\begin{tabular}{|c|c|c|c|c|}
\hline Sector & & & & \\
\hline Unidad & Tumba 12 & Tumba 12 & Tumba 12 & Tumba 8 \\
\hline Capa Sup.Niv. & 1 & 2 & 2 \\
\hline Litros & 2,2 & 2 & 2,2 & 3 \\
\hline Peso (grs.) & 2000 & 1790 & 2000 & 2000 \\
\hline Peso final (grs.) & 14 & 2,4 & $?$ & 3,4 \\
\hline 8 ' & & & & \\
\hline Carbones (núm.) & 45 & 1 & 13 & 3 \\
\hline Peso & 1,4 & 0,1 & 0,2 & 0,1 \\
\hline 16 ' & & & & \\
\hline hoja\#1 & & 1 & & \\
\hline 50 ' & & & & \\
\hline Labiatae & & & 2 & \\
\hline Scirpus & 1 & & & \\
\hline Cactacae\#1 & & & 1 & \\
\hline cf. Euphorbia & & & 1 & \\
\hline Vervena & & & 1 & \\
\hline cf Malvastrum & & & 1 & \\
\hline Solanaceae & & & 1 & \\
\hline Chenopodium & & & 1 & \\
\hline Plantago & 1 & & & \\
\hline Pequeño redondo & & 1 & & \\
\hline No identificado & 1 & & 1 & \\
\hline
\end{tabular}

Tabla 4. Resultados simplificados de la repartición y evolución por unidad de los restos vegetales en Yarcok. 
humanos (4120) proveniente de la chullpa 11. Estuvo asociado al hallazgo del ceramio escultórico consistente de un personaje con sombrero de cuatro puntas. El estrato dos de donde proviene la medición radiocarbónica, pudo ser el nivel de uso de la cámara funeraria pues además de los hallazgos había evidencia de carbones y fragmentos de vasijas utilitarias con impregnaciones de hollín en el exterior de éstas.

\section{Discusión y conclusiones}

Se puede decir que en el Callejón de Huaylas durante el período Horizonte Medio hubo un gran cambio estructural y político, el cual, con la nueva evidencia presentada podría ser fácilmente explicado por absorción, conquista e incorporación política de la región por el Imperio Wari (Isbell 2000:15). Sin embargo, la evidencia también señala un fuerte regionalismo manifestado por tradiciones locales de manufactura lítica usando materiales del lugar, tecnología propia, cerámica tipo Recuay tardío y un estilo arquitectónico de construcción de tumbas tipo chullpa.

\section{Industria Lítica del Horizonte Medio en el Callejón de Huaylas}

Quizás, el más fuerte argumento de interacción regional proviene del sitio de Ancosh Punta. Es una estructura de hábitat estacional asociado a corrales que funcionó exclusivamente durante el período Horizonte Medio (circa 690. 980 AD). La contrastación de lascas con puntas talladas indican manufactura y acabado in situ. Aunque no existen en gran número, la obsidiana merece especial atención debido a la forma de las puntas; punta triangular pequeña de base cóncava y la otra un bifaz largo foliáceo de base recta aplanado. Ambos son estilos de puntas identificados en el Imperio Wari (Burger et. al. 2000:326). De esta última forma, no necesariamente pudo haber sido usada como proyectil sino también pudo tener función de cortar como cuchillo (ibid) y/o herramienta multipropósito sugerido por Bencic (2000:108) para Conchopata, donde aparece la misma forma. Como se ha mencionado, la obsidiana de Ancosh Punta no proviene de fuentes locales, donde al parecer no existen vetas de obsidiana de gran calidad. Todo el material lítico analizado tiene origen geológico local excepto un tipo de obsidiana que fue importada (Grimaldo 1999). Los resultados de los últimos análisis de las muestras de procedencia han confirmado (Burger, Glassock, Lau, Ponte 2006) que, la cantera de Quispisisa localizada en Ayacucho y la de Alca en el Cañón de Cotahuasi, Arequipa fue la obsidiana utilizada en Ancosh Punta. De Quispisisa proviene la mayoría de los artefactos de obsidiana del norte del Perú (Burger et. al. 2000:273). Sin embargo, puntas de obsidiana halladas en Huamachuco, lugar más al norte del Callejón de Huaylas, han sido elaboradas usando la obsidiana de Alca (Burger et. al. 2000:336).

La obsidiana es evidencia económica clave para argumentar la interacción Wari, debido al control político de las redes de intercambio y distribución y en donde el pastoreo y administración de llamas debió estar ligado a procesos de selección de fibra lanar usando la obsidiana como herramienta empleada en el despellejamiento y tratamiento de pieles. Pese a ello, más atención debe merecer el resto del material lítico que resume patrones tecnológicos locales diacrónicos al desarrollo de la complejidad social. En general es poco el número de puntas obtenidos de Ancosh Punta notándose una gran uniformidad en el uso de materia prima (Grimaldo 1999:213). Las puntas pulidas son el rasgo más importante de caracterización local, formas tecnológicas tradicionales que perduran por largo tiempo en la zona de Ancash desde el final del Horizonte Temprano hasta el Horizonte Medio inclusive. Es difícil atribuirles una función específica (Cf. Lavellee 1970:221), no obstante, se puede asumir su posible utilidad en la caza de ani- 
males menores y en conflictos interétnicos (Lumbreras 1980:271). La recurrencia de puntas pulidas en los sitios del área de influencia de Pierina hace pensar sobre su popularidad y para Ancosh Punta, deja en claro su coexistencia con las puntas talladas en obsidiana, es decir, el grupo social está manejando tecnologías locales incorporando estilos panregionales. En el abrigo rocoso de Llaca Amá Caca (PAn 5-58), también existen puntas pulidas asociadas a niveles Horizonte Medio con cerámica similar a Ancosh Punta y contextos de hábitat estacional establecido por pastores.

Un último punto concerniente a la industria lítica de Ancosh Punta es su característica tecnológica sencilla y la variedad de instrumentos recuperados: raspadores (lámina 14), raederas, buriles, cuchillos y puntas de proyectil. Asimismo, es notable la característica rápida y simple, usando tecnología sin esfuerzo (Bencic 2000:90), apreciación que es compartida por Grimaldo (1999) y otros investigadores que analizaron industrias líticas de períodos tardíos. El hallazgo de tres simples agujas de cobre en los pisos de la estructura de Ancosh confirmaría el paulatino cambio de la industria lítica por el uso de metales como buriles y en procesos artesanales de tejido. En ningún caso se encontró herramientas asociadas con actividades agrícolas. Sólo se tienen formas con fines determinados involucrados en el proceso pastoril donde lana y transporte son objetivos primordiales en la utilización del camélido (Aldenderfer 2001:22). Ancosh Punta no contuvo grandes cantidades de puntas ni tampoco Llaca Amá Caca fijándose éste último sólo en niveles Horizonte Medio. La caza pudo ser una actividad secundaria en la puna, donde el pastoreo fue la actividad primordial complementaria a la agrícola.

\section{Estructura tipo Masma para el desarrollo de acti- vidades pastoriles}

No es casual que la estructura habitacional y taller denominada por analogía con los Inkas masma fue emplazada en este lugar la cual tuvo alguna relación con la administración de caméli-
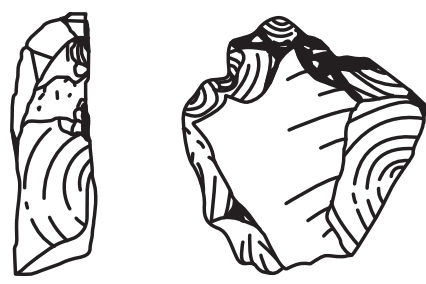

Raspador en hocico Nro. Registro 558-16
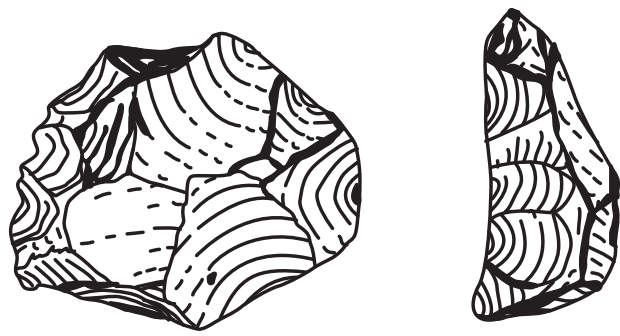

Nro. Registro 509-2

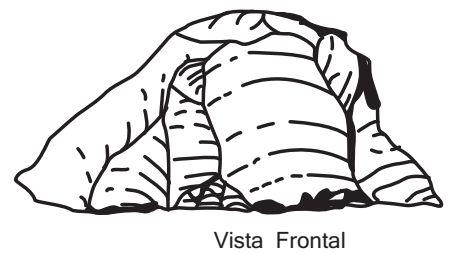

Vista Superior

$6 \mathrm{~cm}$

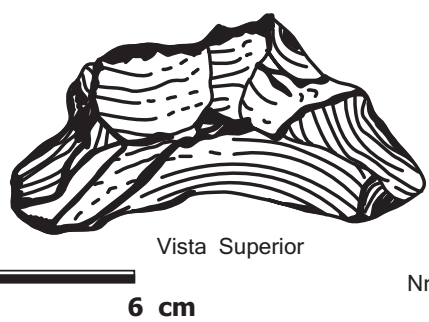

Nro. Registro 599-8

Figura 28. Ancosh Punta (PAn 5-5). Raspadores sobre bloque. 

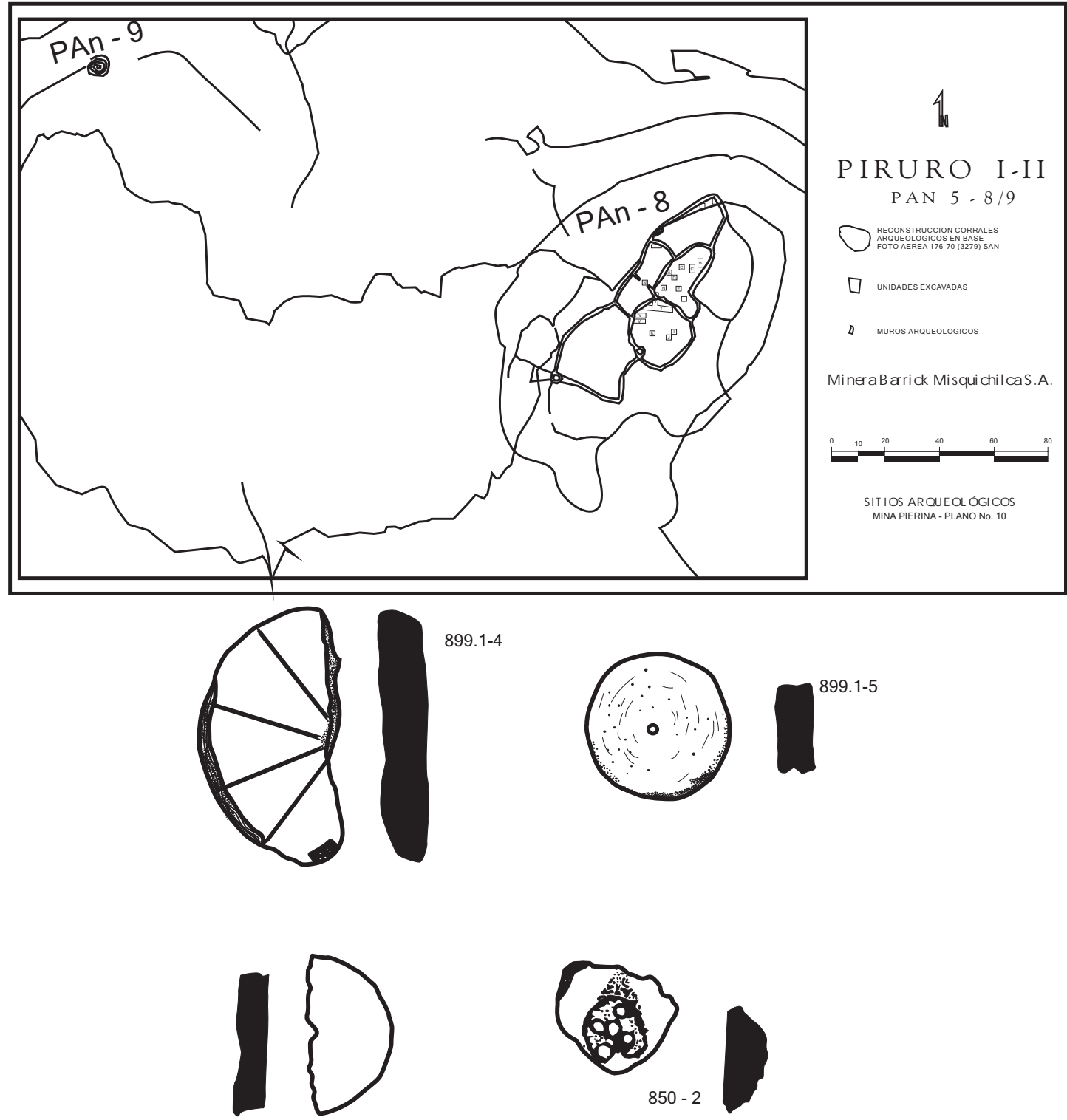

850 - 3

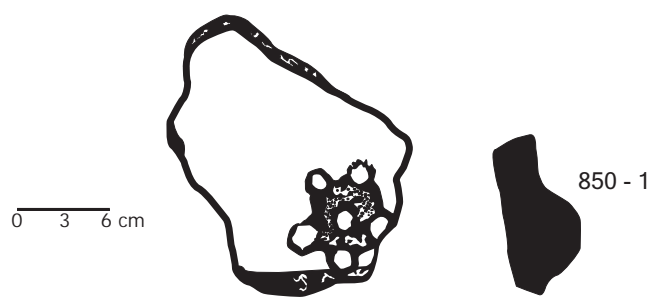

Figura 30. Piruro (PAn 5-8). Piruros y tiestos con decoración plástica. 
dos con fines propios del estado Wari. La presencia de agua permanente propició el crecimiento de pastos en época seca, por lo que se instaló corrales que pudieron ser permanentes. Es común saber que durante la estación seca los recursos se concentran alrededor de fuentes de agua donde animales pueden reunirse en estos remanentes (Rick 1988:9).

Los datos de Ancosh Punta indican incesante preparación de comida para pastores involucrados en el procesamiento de obtención de fibra lanar de las manadas de llamas que permanecían en los corrales. La simple estructura fue habitada probablemente de manera estacional, aunque por la naturaleza de la extensión de la basura desplazada varios metros fuera de la habitación indicaría actividades de limpieza y renovación del piso. Esto último caracteriza asentamientos permanentes (Rick 1988:32-33). Los patrones de formación de basura, incluido el sitio Llaca Amá Caca, señalan una forma diseminada de consumo de cervidos y camélidos, debido a la frecuencia de huesos quemados y cenizas. Este mismo comportamiento puede ser observado en sitios Wari como Piquillacta donde fueron encontrados numerosos fragmentos de huesos quemados en rellenos arqueológicos (McEwan 1991:104). También en Chinchawas, lugar situado en el flanco occidental de la Cordillera Negra, donde en la fase Chinchawasi 2 fechado en 659-875 AD (Lau 2002:table 1) se encuentran fogones y huesos calcinados con cerámica rota que indican preparación de comida (ibid).

La forma cerámica más abundante de Ancosh Punta fueron los platos y cuencos abiertos que contrastan fuertemente a la menor cantidad de vasijas cerradas. Esto implica actividad de servicio de alimentos a un considerable número de personas, reflejado en algún tipo de reciprocidad frente a un servicio prestado de trabajo pastoril. Similares formas alfareras se tienen en el sitio Wari de Jargampata (Isbell 1988:184) y se menciona la posibilidad de ejecución de festivi- dades con bebida y comida propiciadas por el estado. Citando un ejemplo de la Costa Norte, se ha documentado a través de las improntas en adobes, comunidades enteras que prestaban servicios de trabajos rotativos para la construcción de templos y palacios Moche y Chimu (Moseley 1990:26). Estos grupos permanecían en el lugar de trabajo hasta terminar la obra y eran agasajados con bebidas y comida.

La actividad pastoril debió estar vinculada a procesos de manufactura de cuchillos de obsidiana para desollar pieles y obtener lana que luego debió ser hilada utilizando piruros. Estos últimos han sido hallados en forma frecuente en las excavaciones de Ancosh Punta y en el extremo norte de la meseta de Pierina, existía un sitio con corrales denominado Piruro (plano 7), donde también se hallaron gran cantidad de estos instrumentos para el hilado (lámina 15). Los textiles pudieron ser producidos en el piso inferior quechua $(3,500 \mathrm{msnm})$ donde se han detectado varias clases de tumbas Horizonte Medio en torno a Mareniyoc, un centro importante con varias fases de ocupación cultural prehispánica. Actualmente, hay un pueblo sobre el mismo montículo arqueológico cuyos actuales habitantes dedican parte de su tiempo en la elaboración de telares que luego son vendidos en el mercado de Huaraz. Tinyash es otro pueblo encima del río Santa y debajo de la Mina Pierina, donde también se encuentran tejedores actuales, actividad casi siempre desarrollada por varones.

Otro punto importante es la localización estratégica de Ancosh Punta, una planicie en la Cordillera Negra próximo a la cuenca interandina del Santa y también camino a los valles occidentales y a la costa. Aparte de la provisión de lana, los camélidos fueron importantes en el transporte de bienes facilitando las tareas de redistribución durante el Imperio Inka y su posible implicancia con el Imperio Wari (Meddens 1989:146). Del mismo modo, caravanas de llamas son empleadas por campesinos de las zonas 
altas del sur del Perú para transportar productos que luego son comercializados o intercambiados con comunidades de zonas menos frías (Custred 1974:252). La existencia de finos tejidos y camisas Wari o "Moche-Huari" del sitio El Castillo en Huarmey (Prümers 1989:194) localizado en la costa de Ancash pueden provenir de la sierra interandina de Ancash, presunción que se sujeta a la propuesta de Rodman y Fernández (2000:122) de que el centro de producción de tejidos se encontraba en la sierra. En su defecto, la materia prima de lana de camélido pudo ser transportada. No se han hallado aún talleres textiles del Horizonte Medio pero es probable que algunos fueron hechos en la sierra y otros en la costa dada la gran variabilidad.

\section{Cementerio con chullpas en Yarcok}

El conjunto de 22 edificios funerarios o chullpas fueron construidos coetáneamente, hay un sector central tal vez de mayor raigambre por la mejor elaboración arquitectónica de la cámara. Las puertas siempre son dirigidas al este y las ofrendas cerámicas se instalaron en los costados exteriores de las jambas. A diferencia de otros mausoleos como Willcawain (Bennett 1944) y Chinchawas (Lau 2002) donde existen construcciones funerarias subterráneas Recuay y luego se sobreponen edificios tipo chullpa, reflejando cierta continuidad y cambio cultural, en Yarcok tenemos un solo conjunto de tumbas sincrónico y muy uniforme dedicado exclusivamente para cementerio. Todas las chullpas tienen planta rectangular excepto una que sería un tardío antecedente Recuay. Se observa rigidez en la forma rectangular donde lamentablemente no se pudo identificar el número de individuos enterrados ni otros rasgos por la pésima conservación de los huesos humanos. Las chullpas de Yarcok son comparables a dos conjuntos de estructuras también tipo chullpa denominados Pampirca y Piquijirca (Paredes et.al. 2000), localizados en Carhuaz, al norte de Pierina. Estas tienen planta rectangular de mayores dimensiones y con entierros humanos colectivos que pueden corresponder a grupos familiares enterrados en cada estructura.

Por la modalidad del ritual funerario y por la aparición de grupos de estructuras funerarias que responden al concepto moderno de cementerio, se puede argumentar un cambio en el ritual donde en fases precedentes es más común entierros secundarios o reenterramientos como parte de rituales funerarios complejos observados en cámaras subterráneas Recuay del Intermedio Temprano y en sitios Horizonte Medio diversos como Marcahuamachuco (Topic y Topic 2000), Conchopata (Isbell 2000) y Piquillacta (Mc Ewan 1991) relacionados éstos últimos con cultos y celebraciones a los ancestros. No podemos comprobar este fenómeno para las chullpas donde el patrón es más formal y secular donde cada chullpa se vincularía con enterramientos familiares y en conjunto respondiendo a una organización social del tipo ayllu tal como ha sido sugerido (Isbell 1997).

\section{Cronología relativa y fechados radiocarbónicos}

Las mediciones radiocarbónicas obtenidas de los sitios Ancosh Punta, Llaca Amá Caca y Yarcok confirman la cronología absoluta del estilo cerámico Ancosh/Cotojirca IV (650-950 AD) dentro del Horizonte Medio. Asimismo, puede sugerirse una subdivisión donde los sitios habitacionales de puna estaría siendo ocupados durante la primera parte (650-850 AD) mientras que el cementerio de Yarcok sería construido entre 750-950 AD. Los artefactos líticos asociados son datados al Horizonte Medio especialmente por la forma diagnóstica de la obsidiana observable en sitios Wari tanto al sur de los Andes (Fierrowasi, Cerro Baul) en el centro de Ayacucho (Conchopata), en los Andes norteños (Ancosh Punta, Marcahuamachuco) y en la costa norte (San José de Moro). De este último sitio, los contextos de procedencia indican funciones rituales 
y mortuorias asociadas a puntas de obsidiana con individuos masculinos (Castillo 2000:149-150).

Es claro que el estilo cerámico Ancosh/ Cotojirca IV reconoce formas alfareras de uso cotidiano cuyos cuencos abiertos y platos decorados al interior son indicadores de la popularidad de esta clase de vasijas durante la época. Formas similares se les encuentra en Chinchawas donde es posible detectar cuencos con profusión de líneas, puntos y círculos pintados en rojo en la fase Chinchawasi (Lau 2002:figure 6,1-o; figure 10, 1-n), una tardía expresión Recuay, para luego evolucionar a diseños geométricos más simples durante el Horizonte Medio 1B y 2. Patrón evolutivo similar a sido detectado en Huaraz (ver Ponte 2000:fig.12c). Menos frecuente pero también presente son los boles y vasos con engobe negro pulido e incisiones lineales al exterior de éstos, que probablemente sean importados (Bennett 1944:blackware style fig.6c). Esta categoría ha sido también detectada en Huamachuco y es situada en el Horizonte Medio 1B (Thatcher 1975:117). La fina vajilla negra pulida se asocian a los platos y cuencos abiertos con decoración interior y se pueden formular como el material dentro de la primera fase del estilo Ancosh/Cotojirca IV.

De los datos procedentes de las excavaciones de Ancosh Punta y las tabulaciones de los niveles estratigráficos, es ligeramente sugerente que las formas cerradas (jarras, cántaros y ollas) que presentan aplicados, punteados, incisiones cruzadas, protuberancias y estampados circulares en los cuellos podrían ser formas algo más tardías siendo muy populares en el Intermedio Tardío. Posiblemente durante el final de la primera fase del estilo Ancosh/Cotojirca IV, la decoración plástica hace su formal aparición como expresión cerámica local, que por primera vez a sido asociada a fechados radiocarbónicos. Puede ser relacionada a otros estilos cerámicos identificados anteriormente como en Pójoc y Waman Wain donde es llamado estilo Pójoc (Burger
1982 figs.9-15). Lumbreras (1974) le denominó estilo Callejón situándolo en la parte final del Intermedio Temprano y comienzos del Horizonte Medio. Por otro lado, Isbell (1991:34) declara encontrar jarras y boles marrones con decoración plástica tal como apliqués, incisos, punteados y algo de modelados en la última ocupación de Honco Pampa. Esta es datada al final del Horizonte Medio. Finalmente, Grieder (1978:79) estableció la fase Usú en el final de la ocupación de Pashash alrededor del 600 AD. La cerámica es similar a la de Ancosh y los otros sitios mencionados resaltando la continuidad cultural de esta cerámica con Recuay, reemplazando la pintura por la ornamentación plástica. Interesantemente, el estilo también aparece en Huamachuco (McCown 1945:plate 20, o-t).

Aunque los fechados radiocarbónicos con precisión de dos sigmas tienen un lapso de 300 años, espacio temporal demasiado largo para definir cambios culturales cortos (Knobloch 2000:71), la seriación estilística y la comparación ayudan a refinar las fases cronológicas. Tal es el caso de Yarcok, donde la alfarería es muy distinta a Ancosh Punta. Es cerámica funeraria elaborada simultáneamente, mayormente modelados zoomorfos y aves con asa puente y pico tubular. Esta forma es abundante en el estilo Pachacamac de la época 2A con variantes regionales (Menzel 1968:158), lo mismo puede decirse del vaso impreso con la representación de una cara central entre dos felinos de perfil. Tema muy recurrente en la iconografía local Recuay. La posición cronológica relativa confirma la localización tardía de los especímenes de Yarcok dentro del estilo Ancosh/Cotojirca IV.

\section{Comunidad de pastores bajo control Wari en el Callejón de Huaylas?}

La proximidad de la puna de Pierina a zonas con desarrollo agrícola sumado el patrón de asentamiento contemporáneo en donde los poblados se localizan en el piso ecológico quechua pero con 
acceso directo a los pastos de la puna, es evidencia actual que debe ser interrelacionada a los datos arqueológicos proporcionados para inferir el proceso adaptativo cultural de las sociedades del pasado (Gould 1980). Tres actuales comunidades: Cuncashca, Antahuran y Tinyash tenían derechos de acceso a porciones de la puna, tierras que eran separadas por pircas. Cada año, en el mes de Febrero, en época de lluvias, acontecía una celebración patrocinada por la comunidad de Tinyash. Los pobladores se conducían a la puna, a pocos metros del sitio de Ancosh Punta, y llevaban una cruz muy bien decorada a la cual se le reverenciaba con bebida, comida y baile. Entre los pedidos a la cruz, era reproducción del ganado representado por conopas de piedra, que eran dejadas en chozas de pastores eventuales. Es creencia de esta gente, que las conopas de piedra se tornan en animales vivos que acrecientan la productividad y número del ganado (Flores Ochoa 1977). Circunstancialmente, esta costumbre puede tener correlatos con el pastoralismo propuesto para la época Ancosh/Cotojirca IV, y así también fijar el carácter local muy arraigado de sociedades complementarias agrícolas y ganaderas con dioses comunes (Duviols 1974). Sin embargo, la propuesta de una colonia permanente en la puna es poco probable debido a las cortas distancias entre un piso altitudinal y otro, incluido el fondo del valle interandino del Santa.

La evidencia arqueológica balanceada, contrastada y sopesada proveniente de Ancosh Punta conduce a señalar que una instalación completa y diferente al anterior modelo Recuay fue emplazada en la puna con propósitos de obtención de lana de camélidos. Como señalé, la administración de camélidos con Recuay durante la parte inicial y media del Intermedio Temprano debió haber sido menos pronunciada, notándose urgencia por el consumo de textiles por la élite Wari. Por otro lado, la elaboración artesanal fue local usando estilos cerámicos Recuay tardíos o decadentes y formas decoradas que emularían rústicamente cierta interacción Wari. La aparición de la cerámica decorada en forma plástica es claramente local habiendo sido emplazada después de la cerámica negra pulida que junto con los platos y cuencos abiertos pueden corresponder a la influencia Wari durante la primera parte del Horizonte Medio (Isbell 1989:112). No hay indicadores de coacción para señalar dominio Wari, sin embargo, la presión por la actividad artesanal textil pudo ser inducida. Por último, entre los hallazgos de Yarcok destaca la vasija de un personaje con sombrero de cuatro puntas con las manos hacia atrás, esta es la más clara expresión artística Wari. Como se sabe, es común en la vestimenta Wari el sombrero de cuatro puntas, lo cual puede tener ciertas implicancias sobre la función textil y pastoreo que se está planteando para el área bajo análisis.

\section{Agradecimientos}

Este trabajo no hubiese podido ser terminado sin la ayuda económica brindada por Yellow Fox Foundation, Long Beach, California. Mi agradecimiento a Victor Falcón por la paciencia y entusiasmo por cristalizar la publicación.

\section{Bibliografía}

Aldenderfer, Mark

2001 Andean Pastoral Origins and Evolution: The Role of Ethnoarchaeology. Ethnoarchaeology of Andean South America, Contributions to Archaeological Method and Theory. Editado por Lawrence A. Kuznar. Pp.19-30. Ann Arbor.

Angeles, Rommel y Denise Pozzi-Escot

2000 "Textiles del Horizonte Medio. Las Evidencias de Huaca Malena, Valle de Asia". Boletín de Arqueología PUCP, №4 (401-424).

Bartle, Jim

1985 Parque Nacional Huascarán, Ancash-Perú. Lima: Asociación Peruana para la Conservación de la Naturaleza. 
Bencic, Catherine M.

2000 "Industrias Líticas de Huari y Tiwanaku". Boletín Arqueología PUCP № 4:89-118.

Bennett, Wendell C.

1944 The North Highlands of Peru. Excavations in the Callejón de Huaylas and at Chavín de Huántar. New York: Anthropological Papers of the American Museum of Natural History.

Bonavia, Duccio

1996 Los camélidos sudamericanos, una introducción a su estudio. Lima: Instituto de Francés de Estudios Andinos.

Burger, Richard L.

1982 Pojoc and Waman Wain: Two Early Horizon Villages in the Chavin Heartland. Nawpa Pacha 20:3-40.

Burger, Richard L., Karen L. Mohr Chávez y Sergio J. Chávez

2000 Through the glass darkly: Prehispanic obsidian procurement and exchange in Southern Peru and Northern Bolivia. Journal of World Prehistory 14(3)267-362.

Chevalier, Alexander

1999 Informe arqueobotánico del proyecto arqueológico Pierina. Análisis de los asentamientos arqueológicos en el área de influencia de la mina Pierina, Callejón de Huaylas, compilado por Victor M. Ponte. Manuscrito.

Cisneros, Leonor y Luis Guillermo Lumbreras

1980 Historia general del Ejército Peruano. Lima: Editorial Milla Batres. Custred, Glynn

1974 Llameros y comercio interregional. Reciprocidad e intercambio en los Andes Peruanos. Giorgio Alberti y Enrique Mayer compiladores. Pp. 252-289. Lima: IEP.

Castillo, Luis Jaime

2000 "La presencia de Wari en San José de Moro". Boletín de Arqueología PUCP 4:143-180.

Duviols, Pierre

1974 "Huari y Llacuaz, agricultores y pastores. Un dualismo prehispánico de oposición y complementaridad”. Revista del Museo Nacional 39:153-191.

Eisleb, D.

1986 Altperuanische Kulturen: Recuay IV, Museum für Völkerkunde. Berlin.

Flores Ochoa, Jorge A. (compilador)

1977 Pastores de Puna. Lima: IEP.
Gambini, WilfredoE.

1983 Santa y Nepeña, dos valles/dos Culturas. Lima: Universidad Federico Villareal.

Gasparini, Graziano y Luise Margolies

1980 Inca Architecture. Bloomington: Indiana University Press.

Gould, R. A.

1980 Living Archaeology. London: Cambridge University Press.

Grieder, Terence

1978 The Art and Archaeology of Pashash. Austin: University of Texas Press.

Grimaldo, Claudia

1999 Material lítico de los sitios excavados por el Proyecto Arqueológico Pierina. Análisis de los asentamientos arqueológicos en el área de influencia de la Mina Pierina. Compilado por Victor M. Ponte. Manuscrito. Isbell, William H.

2000 Repensando el Horizonte Medio: El caso de Conchopata, Ayacucho, Perú. Boletín de Arqueología PUCP №4 (9-68).

1997 Mummies and Mortuary Monuments: A Postprocesual Prehistory of Central Andean Social Organization. Austin: University of Texas Press.

1991 Honcopampa, Monumental Ruins in Peru's North Highlands. Expedition 33 (3) 27-36.

1989 Honcopampa, was it a Huari administrative centre? The Nature of Wari, edited by R. M. Czwarno, F. M. Meddens and A. Morgan. Bar International Series 525, 98-114.

1988 City and State in Middle Horizon Huari. Peruvian Prehistory, Richard Keatinge editor. Pp. 164-189. London: Cambridge University Press.

Jennings, Justin y Nathan Craig

2001 Politywide Analysis and Imperial Political Economy: The Relationship between Valley Political Complexity and Administrative Centers in the Wair Empire of Central Andes. Journal of Anthropological Archaeology 20, 479-502.

Kaulicke, Peter

1997 Contextos funerarios de Ancón. Esbozo de una sintesis analítica. Lima: Fondo Editorial de la Pontificia Universidad Católica del Perú.

2000 "La sombra de Pachacamac: Huari en la Costa Centra"l. Boletín de Arqueología PUCP, №4: 313-358. 
Knobloch, J. Patricia

2000 "La cronología del contacto y encuentros cercanos de Wari”. Boletín de Arqueología PUCP, №4: 69-88.

Kolff, Helen y Hees Kolff

1998 Flores silvestres de la Cordillera Blanca. Lima: El Instituto de Montaña.

Larco Hoyle, Rafael

s/f Lasultura Santa. Lima: Lit. Valverde, S.A.

Lau, George F.

2002 Feasting and Ancestor Veneration at Chinchawas, North Highlands of Ancash, Peru. Latin American Antiquity 13(3)279. 304.

2000 Espacio ceremonial Recuay. Los dioses del antiguo Perú. Editado por K. Makowski y J.Rucabado, pp.179-197. Lima: Banco de Crédito del Perú.

Lavallée, Danielle

1970 "Industrias líticas del Período Huaraz, procedentes de Chavín de Huántar". Revista del Museo Nacional XXXVI: 193-233.

Lynch, Thomas F.

1985 Chronology of Guitarrero Cave, Peru. Science 229:864-867.

1979 Guitarrero Cave, Early Man in the Andes. Thomas F. Lynch Editor. New York: Academic Press.

1971 "Preceramic Transhumance in the Callejón de Huaylas, Perú". American Antiquity 36 (2) pp.139-148.

1970 Early Human Cultural and Skeletal Remains from Guitarrero Cave, Northern Peru. Science 169:1307-1309.

1967 Quishqui Puncu: A Preceramic Site in Highland Peru. Science 158:780-783.

Makowski, Krzysztof y Julio Rucabado Yong

2000 Hombre y deidades en la iconografía Recuay. Los dioses del antiguo Perú. Colección Arte y Tesoros del Perú. Banco de Crédito del Perú. Pp.199-233.

McCown, Theodore D.

1945 Preincaic Huamachuco. Survey and Excavations in the Region of Huamachuco and Cajabamba. Berkeley: University of California Publications in American Archaeology and Ethnology 39(4).

McEwan, Gordon F.

1991 Investigations at the Pikillacta Site: A Provincial Huari Center in the Valley of
Cuzco. Huari administrative structure, prehistoric monumental architecture and state government. William $\mathrm{H}$. Isbell y Gordon F. Mc Ewan editores. Pp. 93-120. Washington: Dumbarton Oaks Press.

Meddens, Frank M.

1989 Implications of camelid management and Textile production for Huari. The Nature of Wari, A Reappraisal of the Middle Horizon Period in Peru. Editado por R.M. Czwarno, F.M. Meddens y A. Morgan. Pp.146-165. Oxford: Bar International Series 525.

Menzel, Dorothy

1968 La cultura Huari. Lima: Compañía de seguros y reaseguros Peruano-Suiza S.A.

Miller, George R. y Richard L. Burger

1995 Our Father the Cayman, our dinner the Llama: Animal Utilization at Chavin de Huantar, Peru. American Antiquity, 60(3), pp.421-458.

Moseley, Michael E.

1999 The Incas and their Ancestors. New York: Thames and Hudson.

Murra, John V.

1975 Formaciones económicas y políticas del mundo Andino. Lima: IEP.

Paredes, Juan, Berenice Quintana y Moisés Linares

2000 "Tumbas de la época Wari en el Callejón de Huaylas, Ancash". Boletín de Arqueología PUCP №4:253-288.

Ponte Víctor M.

2000 Transformación social y política en el Callejón de Huaylas, siglos III-X D.C. Boletín de Arqueología PUCP №4: 219 . 251. Pozzi-Escot, Denise

1991 Conchopata: A community of Potters. Huari Administrative Structure, Prehistoric Monumental Architecture and State Government. W.Isbell y G.McEwan editores. Pp. 81-92. Washington: Dumbarton Oaks Press.

Proulx, Donald A.

1982 Territoriality in the Early Intermediate Period: The Case of Moche and Recuay. Nawpa Pacha 20: 83-96.

Prümers, Heiko

2000 "El Castillo de Huarmey: Una plataforma funeraria del Horizonte Medio." Boletín de Arqueología PUCP, №4 (289-312).

1990 Tejidos del Horizonte Medio del valle de 
Huarmey. The Nature of Wari, A Reappraisal of the Middle Horizon Period in Peru. Editado por R.M. Czwarno, F.M. Meddens y A. Morgan. Pp. 189-214. Oxford: Bar International Series 525.

Rick, John W.

1988 The character and context of highland preceramic society. Peruvian Prehistory, editado por Richard Keatinge. Pp.3-40. London: Cambridge University Press.

Rodman, Amy Oakland y Arabel Fernández

2000 "Los Tejidos Huari y Tiwanaku: Comparaciones y Contextos". Boletín de Arqueología PUCP, №4 (119-130).

Rofes, Juan

1999 Análisis de los restos de fauna vertebrada recuperados por el Proyecto Arqueológico Pierina, Huaraz, Ancash. Análisis de los Asentamientos Arqueológicos en el Area de Influencia de la Mina Pierina. Compilado por Víctor M. Ponte. Manuscrito.

Schiffer, Michael B.

1986 Formation Processes of the Archaeological Record. Salt Lake City: University of Utah Press.

Schreiber, Katharina J.

1992 Wari Imperialism in Middle Horizon Peru. Anthropological Papers Museum of Anthropology No 87. Ann Arbor: University of Michigan.

Shimada Melody e Izumi Shimada

1985 "Prehistoric Llama Breeding and Herding on the North Coast of Peru". American Antiquity 50(1), pp.3-26.

Stone Miller, Rebecca

1992 Camelid and Chaos in Huari and Tiwanaku Textiles. The Ancient Americas Art from Sacred Landscapes. R. Townsend editor. Pp.335-345. Chicago: The Art Institute of Chicago.
Thatcher, John P. Jr.

1975 Early Intermediate Period and Middle Horizon 1B Ceramic Assemblages of Huamachuco, North Highlands, Peru. Nawpa Pacha 10-12:109-137.

Thompson, Lonnie G.

1995 "Late Holocene Ice Core Records of Climate and Environment from the Tropical Andes, Peru". Lima: Bull. Inst. fr. Études andines 24(3):619-629.

Thompson, L.G., E. Mosley-Thompson, M.E. Davis, P.N. Lin, K.A. Henderson, et. al.

1995 "Late Glacial Stage and Holocene Tropical Ice Core Records from Huascarán, Peru". Science 269:46-50.

Thompson, L.G., M.E. Davis, L. Mosley-Thompson y Kb. Liu

1987 "Pre-Incan Agricultural Activity Recorded in Dust Layers in Two Tropical Ice Cores". Science 336(22/29) 763-765.

Topic, John R. y Theresa Lange Topic

2000 "Hacia la comprensión del fenómeno Huari: una perspectiva norteña". Boletín de Arqueología PUCP 4:181-218.

Valdez, Lidio M., Katrina J. Bettcher y J. Ernesto Valdez

2001 New Wari Mortuary Structures in the Ayacucho Valley, Peru. Journal of Anthropological Research, 58:389-407. Santa Fe: University of New Mexico.

Wilson, David J.

1995 Prehispanic Settlement Patterns in the Casma Valley, North Coast of Peru: Preliminary Results to Date. Journal of the Steward Anthropological Society $23(1 \mathrm{y}$ 2) $187-227$.

1988 Prehispanic Settlement Patterns in the Lower Santa Valley, Perú. Washington: D.C. Smithsonian Institution Press. 